\title{
BAJO LAS AGUAS DEL MAR
}

\section{Algunas consideraciones sobre el relato de Ex 14}

El milagroso paso por el mar de Suf con la consecuente persecución de los egipcios y el desenlace mortal para los opresores en sus aguas constituye uno de los hitos más importantes en los relatos bíblicos de la historia de Israel. ${ }^{1}$ La Escritura aludirá con frecuencia a este acontecimiento prodigioso con el cual YHVH se glorifica a costa del faraón y de su ejército.

Sin embargo, los estudios críticos muestran que el capítulo está lejos de ser una página unitaria. Ningún lector mínimamente informado desconoce el carácter compuesto del relato de la muerte de los primeros opresores de Israel, ahogados en el mar. Más aún: Ex 14 constituye uno de los extraños ejemplos de una doble versión paralela del mismo acontecimiento. $^{2}$ Entre los argumentos principales para tal conclusión se encuentra el hecho de que el relato final presenta tensiones

1 Cf. J. C. GeRTZ, «Tradition und Redaktion in der Exoduserzählung des Pentateuch. Untersuchungen zur Endredaktion des Pentateuch», en FRLANT 186 (2000), p. 189.

2 Cf. J.-L. SKA, Introduction to Reading the Pentateuch. Indiana, Winona Lake, 2006, p. 68. 
irreconciliables ${ }^{3}$ entre sí y que sólo admitirían la posibilidad de un texto homogéneo a costa de un fuerte concordismo o armonización cuestionables. Al menos desde comienzos del siglo pasado, diversos estudios han mostrado que el relato más antiguo no contenía la referencia a un paso milagroso de Israel por medio del mar: "Im Gegensatz zu P wird also von keinem Durchzug berichtet".

El presente trabajo se propone analizar algunos elementos de este relato antiguo y verificar qué ha podido quedar aún a flote de esta primera narración, tras haber sido "cubierto por las aguas" del relato sacerdotal, tradición que ha hecho indudable fortuna. Intentaremos también indagar cuál podía ser su finalidad original.

Dividimos las páginas que siguen en cuatro partes, de extensión desigual: a una presentación de los elementos fundamentales del relato antiguo (1), añadimos un análisis de textos que pueden emparentarse a la acción descripta en Ex 14* (2). Esta comparación nos permite establecer diferencias y semejanzas con los relatos bélicos y con ello acercarnos a la finalidad del relato no sacerdotal (3). Finalmente intentamos rastrear testimonios bíblicos "sobrevivientes" de este relato antiguo (4). Unas breves consideraciones finales cierran nuestro análisis (5).

\section{El relato antiguo}

La constatación de que el relato más antiguo del milagro del mar no contenía la mención de un "paso" de Israel ha ido ganando progresiva aceptación entre los expertos. De allí que nos auto eximamos de una discusión detallada y simplemente nos limitemos a una sucinta presentación. Tal punto de partida nos parece casi de rúbrica. ${ }^{5}$

La complejidad de la materia queda bien ejemplificada por la minuciosa explicación de C. Berner. ${ }^{6}$ En su opinión, el relato más antiguo

3 Una presentación sintética puede verse en J.-L. SKA, Introduction to Reading the Pentateuch. pp. $68-75$.

4 J. C. GeRTZ, Tradition. P. 211. Entre los elencados por el autor se encuentran E. Meyer; W. Rudolph, M. Noth; K. von Rabenau; B.S.Childs, F. Kohata; W. Gross; T. KRÜGER. En su reciente comentario, T. DOZEMANN, Commentary on Exodus. (Grand Rapids, MI - Cambridge, UK), 2009, pp. 298-302, parece ignorar la cuestión.

5 No desconocemos que haya otras propuestas plausibles. Una discusión detallada puede verse en C. BERNER, «Die Exoduserzählung. Das literarische Werden einer Ursprungslegende Israels», en FAT 73 (2010), 343-353. Nuestra síntesis de la materia sigue en parte esta obra.

6 El exégeta divide la historia de la composición en tres períodos fundamentales: pre sacerdotal, sacerdotal y post sacerdotal. Además, individua 
comienza en Etam, al borde del desierto $(13,20)$. Esta "Itinerarnotiz" es la continuación originaria de la información suministrada en $12,37 \mathrm{a}$ donde Sukkot era la primera estación del camino. ${ }^{7}$ El rol destacado de la columna de nube en este relato $(14,19 b-20.24)$ supone una introducción apropiada: de allí que la mención de la protección de YHVH que los precede en una columna de nube para señalarles el camino haya de

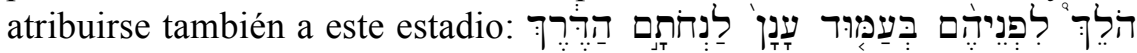
(1) וַיהוָֹה encuentra sin artículo, en estado indeterminado.

La siguiente escena es el noticia de la partida de los israelitas que recibe el rey de Egipto $(14,5 \mathrm{a})$ y la preparación del carro para poder perseguirlo $(14,6)$. Berner excluye del relato antiguo el v. $14,5 b$, entre otras razones, porque el arrepentimiento de haber permitido la partida de sus esclavos supone el final del ciclo de las plagas con la muerte de los primogénitos, que ha de datarse posteriormente. ${ }^{8}$ J.-L. Ska, por el contrario, destaca la diferencia con el vocabulario sacerdotal: aparece el verbo הפך que "décrit un changement profond". ${ }^{9}$ No se percibe, al menos directamente, una intervención divina y la acción se atribuye más bien al Faraón. Tampoco aparece el motivo típico del sacerdotal del "endurecimiento del corazón".

nada menos que 14 "Bearbeitungen" (!) que habrían intervenido en la composición que, no rara vez, fueron corrigiendo los déficits o tensiones provocados por la intervención inmediatamente anterior. Cf. C. BERNER, Die Exoduserzählung, pp. 400-405.

7 Cf. C. BERnER, Die Exoduserzählung. p. 343. Aquí el autor se remite, entre otros, a J. C. GERTZ, Tradition. p. 207-208. Para el autor, a diferencia de otros, „Die Itinerarnotiz in 12, 37a ist für die nichtpriesterschriftliche Exoduserzählung unverzichtbar und gehört nicht zu P“(n. 77).

8 Cf. C. BERNER, Die Exoduserzählung. p. 345. Nos preguntamos si aquí no nos encontraríamos, por tanto, con una "Lücke" en el relato más antiguo. Una de sus razones fundamentales para excluir la existencia de un relato sacerdotal y optar por un "Forschreibungsprozess", es precisamente la presencia de "lagunas" en el sacerdotal y que "in der Forschung gerne übersehen werden". Cf. ID., Die Exoduserzählung. p. 354. Por otra parte, su conclusión "Ex 14, 5a lässt keinen Zweifel daran, dass die Israeliten ursprünglich einfach geflohen waren" (ID., Die Exoduserzählung. p. 345), desconoce otras posibilidades de traducción del verbo ברח. Para la discusión sobre la naturaleza de la tradición sacerdotal, cf. M. VERVENNE, "The ' $P$ ' Tradition in the Pentateuch: Document and/or Redaction? The 'Sea Narrative (Ex 13, 17-14, 31) as a Testcase», en C. BREKELMANS - J. LUST (eds.) Pentateuchal Studies and Deuteronomistic History. Leuven, 1990, pp. 67-70; J.-L. SKA, «De la relative indépendance de l'écrit sacerdotal», Bib 76 (1995), pp. 396415.

${ }^{9}$ Cf. J.-L. SKA, «Le passage de la mer. Étude de la construction, du style et de la symbolique d'Ex 14, 1-31», en AnBib 109 (1986), p. 53. 
Tampoco 14, 7-9 pertenece, a juicio de Berner, al relato pre sacerdotal. $^{10}$ Originalmente no contenía una información sobre la persecución y el narrador se movió sólo desde el punto de vista ${ }^{11}$ de Israel:

Im vorpriesterschriftlichen Bestand des Meerwunderberichts wurde die Verfolgung durch die Ägypter im Anschluss an Ex 14, 5 b. 6 nicht einfach notiert, sondern aus der Perspektive der lagernden Israeliten eingeholt (14, 10b): ,Da hoben die Israeliten ihre Augen, und siehe, die Ägypter zogen hinter ihnen her. Da fürchteten sie sich sehr'.12

Sin embargo, a nuestro juicio, con ello nos encontraríamos ante una "Lücke" de consideración en el relato antiguo: sin la mención de una persecución el relato perdería coherencia. El narrador no habría informado sobre un movimiento fundamental. Por otra parte, el autor no tiene en cuenta el duplicado de $14,8 \mathrm{~b}$ en $14,9 \mathrm{a}$ que hace presentir, con cierto fundamento, que nos encontramos ante una superposición de datos, provenientes de diversos relatos.

A lo dicho podemos agregar que la secuencia de los verbos רדף y נשי

$\mathrm{Al}$ darse cuenta de la persecución, ${ }^{14}$ Israel reacciona con el miedo

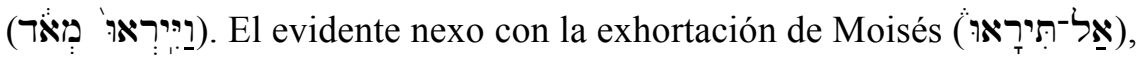

10 Cf. C. BERNER, Die Exoduserzählung, p. 345. Menciona que 14, 9a en relación a 14, 8a "nochmals jünger ist" y la presencia del pronombre supone a su juicio que el versículo retoma el objeto de 14, 8a.

11 Una presentación sucinta sobre el "Punto de vista" puede verse en D. MARGUERAT, «ll 'Punto di vista' nella narrazione bíblica», en RivBib 3 (2010), pp. 331-353.

12 C. BERnER, Die Exoduserzählung. p. 346.

13 Cf. J.-L. SKA, Le passage de la mer. pp. 60-61.

14 La clasificación del v. 10 es difícil. A favor de la pertenencia al sacerdotal

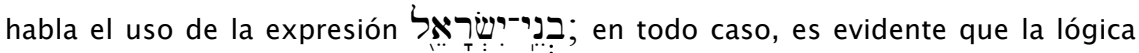
del relato lo exige. Posiblemente nos encontremos en un caso de overlap entre los dos relatos que no pueden narrar dos veces lo mismo. Tampoco podríamos excluir

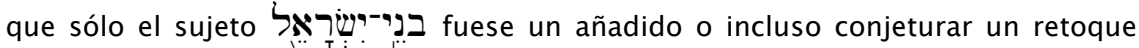
deuteronomista: en el libro del Deuteronomio la expresión se encuentra veces más de una veintena de veces: Dt 1,$3 ; 3,18 ; 4,44.45 .46 ; 10,6 ; 23,18 ; 24,7 ; 28,69$; $31,19(2 x), 22.23 ; 32,8.49 .51(2 x), 52 ; 33,1 ; 34,8.9$. sería un fenómeno análogo a la posible adición "Siervo de YHVH" en Ex 14, 31. Cf. J.-L. SKA, «Ex xiv contient-il un récit de «guerre sainte» de style deutéronomistique ?», en VT 33 (1983), p. 463. La mención del "grito" de los hijos de Israel aparece en Jue 4, 3. Sobre un supuesto "estilo deuteronomista" del relato, nos ocupamos más adelante. 
nos permite "separar las aguas" entre el relato antiguo y los elementos de posterior proveniencia. El grito desesperado que los hijos de Israel

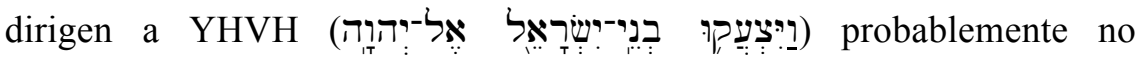

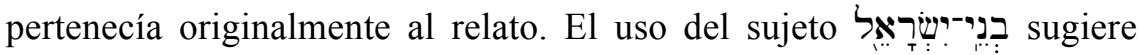
que se trata de una frase del relato sacerdotal. Prepara el discurso que YHVH dirigirá a Moisés $(14,15-18)$, si bien nos encontramos con la extrañeza de que YHVH le reprocha a Moisés en persona el haber gritado, aunque el texto no lo dice explícitamente. ${ }^{15}$

El carácter tardío de las murmuraciones del pueblo $(14,11-12)$ $\mathrm{y}$, por tanto, su ausencia en el relato primitivo es objeto de amplio consenso. ${ }^{16}$ El anuncio de la salvación de YHVH por parte de Moisés $(14,13-14)$ es la continuación lógica del climax creado por el descubrimiento de los perseguidores por parte del pueblo de Israel. Este

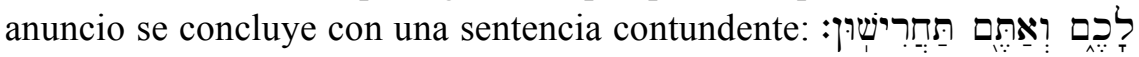

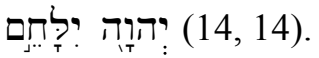

La siguiente escena describe el desplazamiento a la retaguardia de

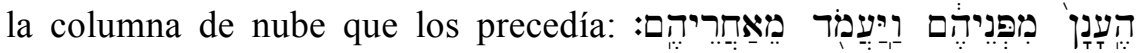

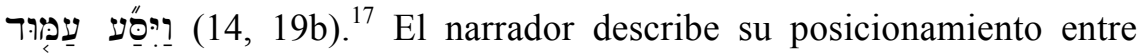
ambos campamentos: (14, 20). La consecuencia de tal posicionamiento estratégico de la columna de nube es el impedimento de un acercamiento entre ellos: (14, 20b).

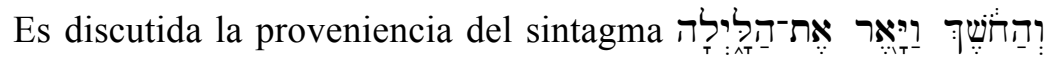

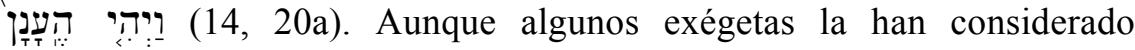
original, ${ }^{18}$ sin embargo es mucho más probable su proveniencia posterior,

15 ¿Una escena del relato sacerdotal omitida en la redacción final por ser incompatible con el discurso de Moisés al pueblo?

16 Cf. C. BERNER, Die Exoduserzählung. p. 346; J.-L. SKA, Introduction to Reading the Pentateuch. pp. 76-77.

17 Sobre el carácter tardío de 14, 19a, nos basta con dar la palabra a J. C. GERTZ, Tradition. p. 219: "Die literarische Priorität kommt dabei ohne Zweifel V.19b zu. Während der Bote Gottes in V. 19a neu eingeführt wird und im Fortgang der Erzählung keine Rolle mehr spielt, steht die Wolkensäule aus V. 19b in einem Aussagezusammenhang, der sich schwerlich aus der nichtpriesterlichen Version der Meerwundererzählung ausgliedern lässt“. Nos pertenece la cursiva.

18 Cf. C. LEVIN, «Source Criticism. The Miracle at the Sea», en (Hrsg. J.M. LEMON - K.H. RiChards), Method Matters. Festschrift D.L. Petersen, Atlanta, 2009, p. 55; E. BLUM, «Die Feuersäule in Ex 13-14 - Eine Spur der 'Endredaktion'?», ID, Textgestalt 
al menos parcialmente. ${ }^{19}$ No es imperceptible la tensión creada por la aparición de la luz en la noche:

Ungeachtet aller Harmonisierungsversuche steht das Erleuchten der Nacht in Spannung zu der davor erwähnten Finsternis. Im Gegensatz zu dieser passt das Leuchten aber auch nur schlecht zu der folgenden Aussage von 14, 20b, nach der sich beide Heerlager die ganze Nacht einander nicht genähert haben. 20

Esta separación entre los dos campamentos gracias a la intervención de la columna de nube no puede ser más que un primer paso. Esta descripción de la separación durante segunda acción divina: YHVH desplazó el mar con un viento fuerte del Este que sopló precisamente durante la noche entera $(14,21 b) . \mathrm{Su}$ continuación, siguiendo a Berner, ${ }^{21}$ la encontramos en 14, 24:

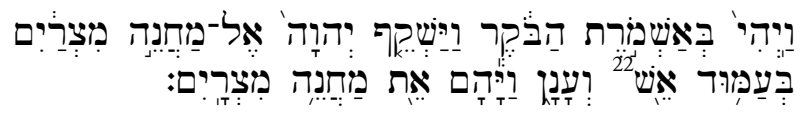

La nueva indicación temporal trae consigo una nueva intervención. El desarrollo de la acción había quedado en suspenso ya que durante

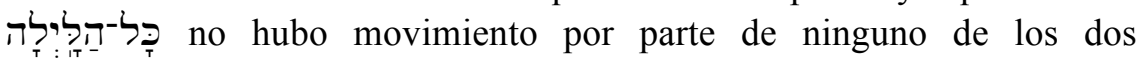

und Komposition. Exegetische Beiträge zu Tora und Vordere Propheten, en FAT 69 (2010), pp. 154 ss. Citados en C. BERNER, Die Exoduserzählung. p. 347, n. 19.

19 Cf. C. BERNER, Die Exoduserzählung. p. 372; W. Gross, «Die Wolkensäule und die Feuersäule in Ex 13+14. Literarkritische, redaktionsgeschichtliche und quellenkritische Erwägungen», en Festschrift Norbert Lohfink (Hrsg. G. BRAULIK - W. GROSS - S. MCEVENUE), Biblische Theologie und gesellschaftlicher Wandel. Freiburg i. Breisgau, 1993, pp. 142-165. Si el desplazamiento de la columna de nube se supone mientras aún es de día, nos encontramos con un gap: hasta ahora no ha habido ninguna mención de la llegada de la noche y la afirmación de 14, 20b aparecería de manera abrupta. De allí que

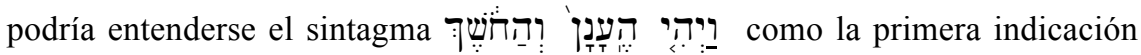
de la llegada de la noche que contenía el relato más antiguo.

20 J. C. GERTZ, Tradition. p. 210.

${ }^{21}$ Cf. C. BERNER, Die Exoduserzählung. p. 347.

22 Nos distanciamos de C. BERNER, Die Exoduserzählung. p. 348, para quien

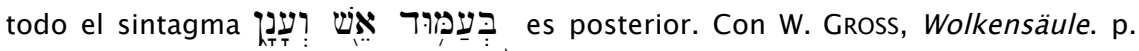

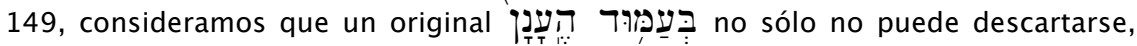
sino que además se encuentra en perfecta coherencia con 14, 19. 
campamentos. No hubo más que una única acción: el desplazamiento del mar debido al viento del este.

El narrador antiguo utiliza el verbo המם para describir el accionar de YHVH: con él se expresa una acción contundente que tiene como consecuencia necesaria la huída de los enemigos. En el acápite siguiente nos ocuparemos de la expresión.

La reacción del enemigo frente a esta confusión provocada por la

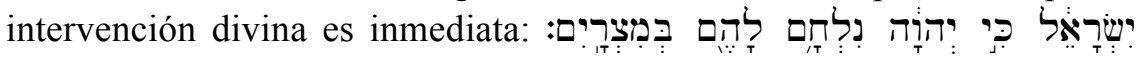

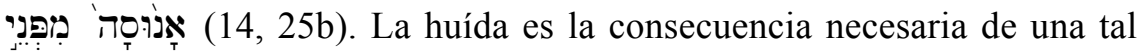
intervención y su fundamento es la percepción de lo anunciado por Moisés: YHVH se convertirá en guerrero a favor de su pueblo $(14,14 a)$.

La descripción de esta acción de confundir el campamento egipcio contenida en 14, 25a es discutida. Para Berner es evidente que se trata de una formulación coherente con la lógica de la Fortschreibung sacerdotal:

Dass das kriegerische Eingreifen der Gottheit auch einen hemmenden Einfluss auf die Räder der ägyptischen Streitwagen einschloss (14, 25a:

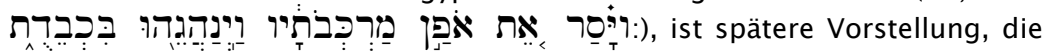
der priesterschriftlichen Konzeption des Meerwundes als Verfolgungsjagd durch das geteilte Meer Rechnung trägt. Nun müssen die Ägypter ausgebremst werden um zu verhindern, dass ihr in 14, 25b geäußertes Fluchtvorhaben ein Entkommen aus der präparierten Todesfalle ermöglicht, die in Gestalt der sich an beiden Seiten auftürmenden Wassermauern auf ihre ägyptischen Opfer wartet. Der ursprüngliche Erzähler konzipierte den Untergang der Ägypter genau andersherum, denn hier ist eine Flucht geradezu erforderlich, um die Verfolger in das zuvor ausgetrocknete Meer zu treiben, den am Morgen zurückflutenden Wassermassen entgegen.23

Si bien esta explicación es bastante plausible, cabe todavía hacer algunas observaciones. El vocabulario del versículo es ciertamente poco usual. Por otra parte, no existe la más mínima insinuación de una acción semejante en el discurso sacerdotal inmediatamente anterior de YHVH a Moisés (14, 15-18). La acción de "apartar la rueda de los carros" atribuida a Dios no parece reflejar la teología sacerdotal. Es una acción demasiado "humana". El verbo סור supone como sujeto a YHVH en tres de las nueve plagas de origen no sacerdotal (Ex 8, 4. 27; 10, 17). ${ }^{24}$

23 Cf. C. Berner, Die Exoduserzählung. p. 348.

24 Cada plaga pertenece a cada una de las tres series en las que se pueden dividir las nueve. Cf. F. GARCía LÓPEZ, El Pentateuco. Introducción a la lectura de los 
Ahora bien, ¿qué función podría tener una lentificación en la huída cuando es precisamente lo que se espera? Proponemos una explicación posible a partir de las indicaciones temporales del relato antiguo.

YHVH comienza dirigiendo su mirada desde la nube hacia el campamento de Egipto e inmediatamente los confunde infundiéndoles pánico. Esta primera intervención tiene lugar durante la vigilia de la

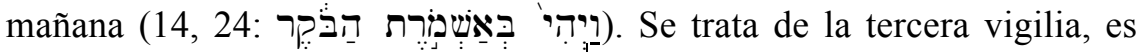
decir de 2 a 6 de la mañana. Cabría entonces pensar que el viento aún no ha dejado de soplar durante parte de esa vigilia, ya que su acción se

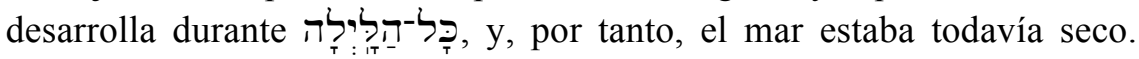
Según el narrador, éste vuelve a su lugar recién al amanecer (14, 27: לפבְנוֹת hubiesen podido huir a salvo.

No obstante, es cierto que en la hipótesis de pertenecer al relato más antiguo el lugar del versículo crea una pequeña dificultad: se hace referencia al movimiento dificultoso de la rueda $(14,25 \mathrm{a})$ antes de la decisión de huir $(14,25 b)$. De allí que se haya afirmado con razón que el versículo aparece demasiado pronto en el relato. ${ }^{25}$ La objeción es atendible y por ello puede ser entendido como un añadido posterior, pero previo al trabajo sacerdotal: un ojo atento habría podido ver la necesidad de "dificultar" la huída y dejar así un tiempo suficiente para que al retorno del mar la tropa egipcia se encontrara con él. El lugar elegido fue precisamente a continuación de la confusión y del pánico infundidos por YHVH.

El narrador antiguo continúa su relato mencionado el

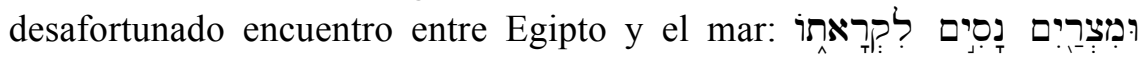
(14,27b). El mar vuelve a su flujo mientras Egipto está huyendo inadvertida y dificultosamente a su encuentro. El

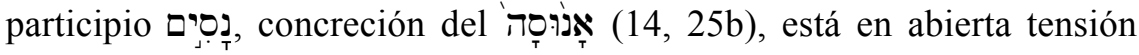

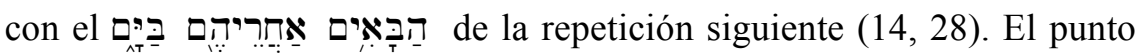
álgido de la narración se encuentra en la acción siguiente atribuida a

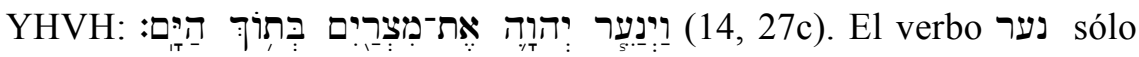

cinco primeros libros de la Biblia. Estella, Navarra, Verbo Divino, pp. 159-162. Además YHVH aparece como sujeto en Ex 23, 25; 33, 23.

25 Cf. F. KOHATA, «Jahwist und Priesterschrift in Exodus 3-14», en BZAW 166 (1986), p. 289. 
volverá a tener a YHVH como sujeto en el gran Hallel (Sal 136, 15) y en la apología de la administración de Nehemías (Neh 5, 13). Significa normalmente "sacudir" o "arrojar" y suponen un cierto movimiento físico. ${ }^{26}$ El canto de Miriam en 15,21 b parece aludir a la misma idea. ${ }^{27} \mathrm{El}$ efecto totalmente devastador queda claro con la fórmula final de sabor

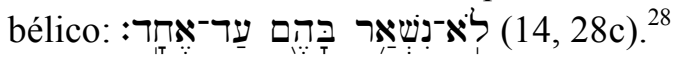

La descripción de Ex 14, 30-31 cierra el relato y refleja el cumplimiento de la exhortación de Moisés al pueblo (Ex 14, 13-14). ${ }^{29} \mathrm{~A}$ la constatación de Egipto de la intervención divina para salvar a su pueblo $(14,25 \mathrm{~b})$, sigue el mismo reconocimiento, pero en "ojos" diversos: ahora es el pueblo que ha visto cumplida la salvación anunciada.

Con ello asistimos al cierre de un ciclo que, en opinión de Berner, ha comenzado junto a la zarza. Allí se habla por primera vez de una

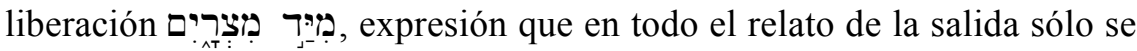
repetirá en 14,30 :

Mit 14, 30 schließt sich dieser Kreis (i.e., con 14, 13-14): ,Und JHWH rettete die Israeliten an diesem Tag aus der Hand der Ägypter (...), und die Israeliten sahen die Ägypter tot am Ufer des Meeres liegen“(...). Der Vers bildet jedoch nicht allein einen bündigen Abschluss der vorpriesterschriftlichen Meerwundererzählung, sondern weist gleichzeitig auch über seinen direkten literarischen Kontext hinaus zurück auf den Beginn der Exoduserzählung. So bedeutet die in 14,30a konstatierte Rettung aus der Hand der Ägypter auch eine Erfüllung der programmatischen Erklärung JHWHs, er sei herabgestiegen, um sein Volk aus der Hand der Ägypter zu befreien (3, 8a a). ${ }^{30}$

El hilo de la narración se retoma en Ex 15, 22, cuando Israel abandona definitivamente el Mar de Suf para adentrarse en el desierto.

\section{Analogías literarias de la destrucción de un ejército}

26 Cf. Jue 16, 20; Neh 5, 13; Job 38, 13; Sal 109, 23; Is 33, 9. 15; 52,2.

27 Cf. C. BERNER, Die Exoduserzählung. pp. 389-391.

28 Cf. J.-L. SKA, Le passage de la mer. p. 116 : “...plusieurs récits de bataille se terminent en effet par une formule semblable à celle d'Ex 14, 28."

29 Cf. la discusión infra 11 ss.

30 Cf. C. BERnER, Die Exoduserzählung. p. 349. 
Si esta reconstrucción propuesta del relato más antiguo del milagro del mar es plausible, deberíamos encontrar semejanzas o analogías en la Escritura. ¿Es posible encontrar otro texto o relato en el cual un ejército sea destruido en modo semejante al descripto en la versión no sacerdotal de Ex 14?

Obviamente que la descripción de Ex 14, aun en su versión más antigua, es un relato del todo singular. No encontramos analogías completas en la Escritura. Sin embargo, es posible descubrir en él algunos elementos que nos permiten asociarlo a algunos relatos bélicos en los cuales la intervención de YHVH es decisiva e Israel no tiene un rol activo en la derrota del enemigo.

Se ha hablado a menudo de "guerra santa". 31 Sin embargo, tal caracterización no ha quedado sin contestar: "Pour $P^{g}$, il n'y a pas de combat. Pour J, la question est un peu différent. Il utilise la terminologie de la guerre saint, mais il la remanie profondément". ${ }^{32}$ No podemos hablar ciertamente de una guerra santa no sólo porque no hay un verdadero combate ni escenario bélico sino además porque Israel no se presenta como un ejército "armado". ${ }^{33}$ es un pueblo que huye de una situación de opresión y de esclavitud. No obstante, hay elementos que pueden considerarse cercanos a la imaginería e ideología bélicas, sin representar un relato de guerra santa:

Das Auffällige und Bemerkenswerte an der vorjahwistischen ${ }^{34}$ Meerwundergeschichte liegt darin, dass sie, obschon in der Darstellung durch und durch von der Jahwekriegsideologie her geprägt, im eigentlichen

31 Cf. G. von RAD, «Der Heilige Krieg im alten Israel» en ATANT 20 (1951). El autor elenca las diferencias especialmente en las pp. 9-10. 45-47.

32 J.-L. SKA, Le passage de la mer. p. 50. n. 25; Aquí el exégeta belga discute fundamentalmente la vinculación de la temática del endurecimiento del corazón a la guerra santa: "En conclusion, il semble préférable de considérer l'endurcissement du cœur comme un thème sans lien spécifique avec la guerre sainte. Par quelques remarques, on a déjà suggéré une autre voie: le jugement prophétique". cf. también J.-L. SKA, «Ex xiv contient-il un récit de «guerre sainte» de style deutéronomistique?», pp. 454-467; P. WEIMAR, «Die Jahwekriegserzählungen in Exodus 14, Josua 10, Richter 4 und 1 Samuel 7», en Bib 57 (1976), pp. 38-72.

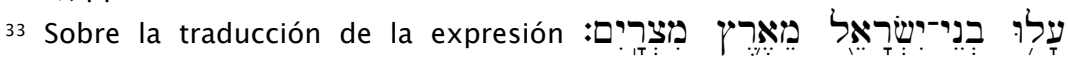

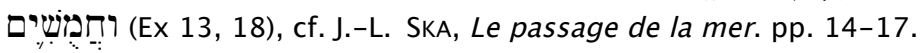

34 Obviamente nos distanciamos de la atribución a un estadio "preyahvista" que hacía el autor por los años 70. 
Sinne überhaupt kein kriegerisches Geschehen darstellt. So kann man die „Kriegsansprache” in Ex 14, 13a*.14 nahezu als eine „Anti-Kriegsansprache“ bezeichnen. ${ }^{35}$

Conscientes de esta diferencia profunda, ${ }^{36}$ analizamos, no obstante, las semejanzas que podemos rastrear y que constituyen en cierto sentido el Background conceptual del primer relato del acontecimiento del mar de Suf. Analizamos fundamentalmente algunos textos que contienen la raíz המם, con la que el relato antiguo describe la acción principal de YHVH $(14,24) .{ }^{37}$ Su función, no es secundaria:

Aber auch nach der gewissermaßen im Zentrum stehenden ,Kriegsansprache', die nur in Ex 14, 13a und Jos 10, 8a mit der Formel ,fürchtet dich nicht!' eingeleitet ist, zeigen die vier Jahwekriegserzählungen bemerkenswerte Übereinstimmungen im Aufbau, auch wenn hier als festes, alle Geschichten durchziehendes Element nur das ,Verwirren' durch Jahwe angegeben werden kann, worum sich alle weiteren Glieder gruppieren. ${ }^{38}$

\subsection{La estrategia (programática) de YHVH (Ex 23, 20-33)}

Tras el relato de la llegada al Sinaí y la promulgación del decálogo (Ex 19, 1 - 20,21) y del Código de la Alianza (20, 22 - 23, 19), el libro del Éxodo concluye con una serie de promesas e instrucciones que preparan la entrada en Canaán $(23,20-33)$. Espigamos algunos versículos:

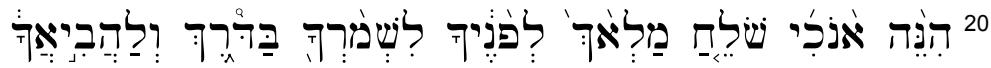

35 P. WEIMAR, «Die Jahwekriegserzählungen». pp. 40-41.

36 Una descripción breve pero suficiente de las semejanzas y diferencias formales puede verse en P. WEIMAR, «Die Jahwekriegserzählungen». pp. 70-73.

37 Si bien nuestra opción es parcial, no obstante optamos por un terminus technicus: "Das qal von hmm wird im AT einschließlich Sir 10mal mit dem Subjekt JHWH gebraucht; in gleicher Weise wird hwm Deut 7, 23 verwendet. Beide Verben sind in dieser Verwendung 9mal terminus technicus für das Hervorrufen einer panischen Bestürzung, des sog. Gottesschrekkens. Sie begegnen dementsprechend in Berichten von JHWH-Kriegen (Ex 14, 24; Jos 10, 10; Ri 4, 15; 1 Sam 7, 10), womit der Rückblick Sir 48, 21 zu vergleichen ist, und in den generalisierenden Siegesankündigung Ex 23, 27 und Deut 7, 23. Objekte sind die Feinde JHWHs und Israels, speziell das feindliche Kriegslager": H.-P. MüLLER, « mh», en ThWAT II, pp. 449-454. 450. Otros textos que no tratamos: 2 Sm 22,15; Sal 18,15; 144,6.

38 P. WEIMAR, «Die Jahwekriegserzählungen». p. 71. 

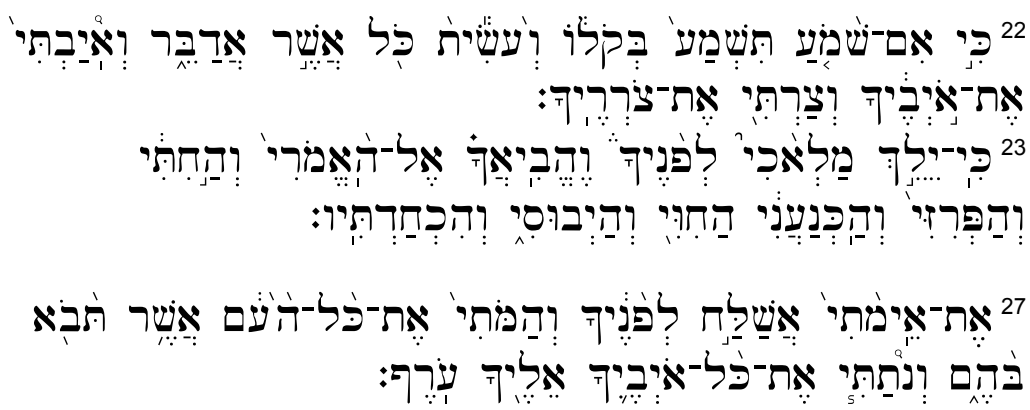

El texto deja traslucir una influencia o redacción deuteronomista ${ }^{39}$. Incluso podemos notar la semejanza con Dt 7, 17-26, donde el autor establece explícitamente un nexo con lo realizado por YHVH contra el Faraón y contra todo Egipto (Dt 7, 18-19) y con esta experiencia

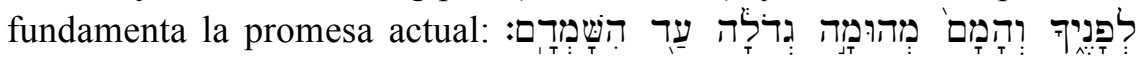

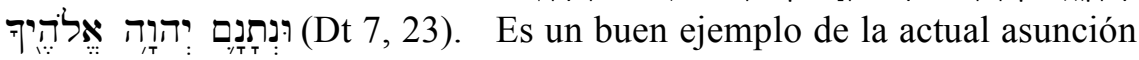
de que el Tetrateuco ha conocido redacciones provenientes de esta corriente ideológico-teológica. Mientras que es complejo identificar sus rastros en el libro del Génesis, el libro del Éxodo ofrece, según opinión generalizada, importantes ejemplos:

The situation is very different in the book of Exodus, where we find numerous Deuteronomistic texts and features, as for instance 'the list of peoples' in the story of Moses' call (Exod. 3.8) or the prescriptions of Exod. 23. 23-33 for the separation from, and expulsion of, foreign peoples. 40

En concreto, nos parece poder identificar un núcleo común con el relato antiguo de Ex 14: YHVH toma posición a favor de Israel; sus enemigos y adversarios son los propios. Israel no tiene más que escuchar y obedecer, en este caso, al ángel. ${ }^{41}$ Se destaca la acción de YHVH: enviará delante su terror y confundirá a los pueblos que salgan a su paso.

39 Cf. T. RÖMER, The So-Called Deuteronomistic History. A sociological, historical and literary introduction. New York, 2007, pp. 33-35.

40 T. RÖMER, The So-Called Deuteronomistic History. p. 34.

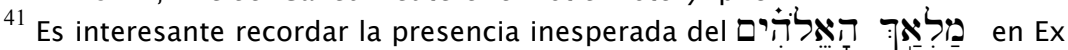
14, 19. Aparece de improviso y no desempeña ninguna función ülterior. Ya hemos afirmado que con toda probabilidad se trata de un añadido posterior. La semejanza de los textos nos permite sospechar una dependencia literaria. 
La consecuencia de esta intervención de YHVH será contundente: la

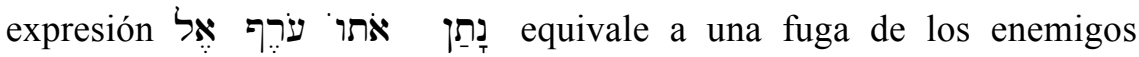
seguida de su destrucción por parte de Israel. No se trata de una entrega de los enemigos en el campo de batalla o en medio de la lucha, sino durante su huída, es decir, ya vencidos. ${ }^{42}$ El nexo entre la acción de confundir de YHVH y la huída inmediata de los enemigos es quizás el quicio de la imagen. A esta fuga se sigue siempre una actividad suplementaria de Israel; Ex 14 refleja, no obstante, una particularidad singular: el arrojo del ejército en el mar y su deceso por anegación toma el lugar del exterminio complementario que en los demás relatos realiza Israel. ${ }^{43}$ Para Ex 14*, "sólo YHVH basta".

\subsection{La coalición amorrea contra Gabaón (Jos 10, 1-15)}

El célebre relato de la lucha en Gabaón, donde el "sol se detuvo" (Jos 10,13) presenta asimismo una intervención divina decisiva con la cual Israel se asegura su victoria. YHVH se dirige a Josué y lo exhorta a la confianza: אַל־תיתירָא (Jos 10, 8). Tras la llegada improvista de Josué y su ejército al campamento enemigo, Dios mismo realiza la acción principal:

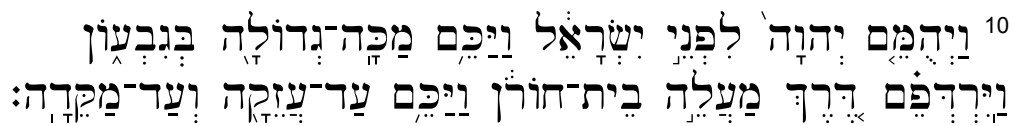

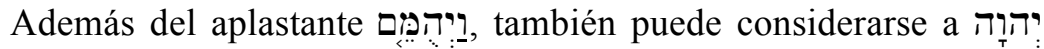

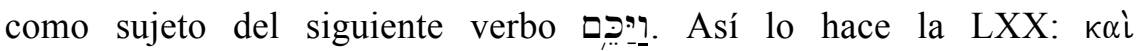

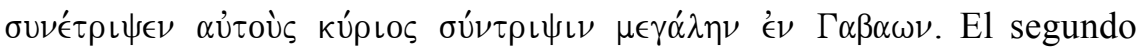

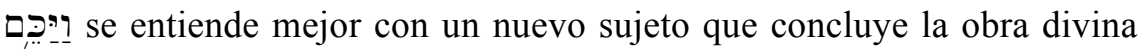
con la persecución del enemigo. De manera análogo al relato de Ex 14, la

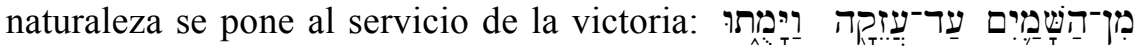
(10,11). El autor remata su relato

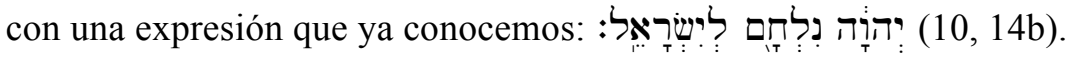

La exégesis crítica ha puesto de relieve los parentescos literarios

${ }^{42}$ Cf. 2 Sm 22, 41; Sal 18, 41.

${ }^{43}$ Cf. P. WEIMAR, «Die Jahwekriegserzählungen». p. 71. 
con relatos de conquista asiria y por ello es posible datar una primera edición del libro de Josué entre el VIII y VII siglo a.C. Si bien el mismo motivo aparece ya en la estela del rey moabita Mesá, datable aproximadamente a mediados del siglo IX, ${ }^{44}$ los paralelos más cercanos se encuentran en los documentos neoasirios. ${ }^{45} \mathrm{La}$ función parece clara:

\begin{abstract}
...the most favourable social and political context for the beginnings of the Deuteronomistic literary activity is the time of Josiah. Like Deuteronomy, the first edition of Joshua would have served very well the national policy of Josiah and his advisers. This edition probably probably consisted almost exclusively of narratives of battle and conquest; imitating the genre of Assyrian propaganda, it was aimed at affirming Judah's political and military independence, at a time when Assyrian influence was declining in the region. As a result, the Judean god Yahweh was presented as taking over the main characteristics of the Assyrian national god Assur and as being, therefore, the warrant for the political autonomy of this people. ${ }^{46}$
\end{abstract}

\title{
2.3. La victoria junto al Torrente de Quisón (Jue 4, 1-23)
}

El pecado de Israel puso al pueblo a merced de Yabín, rey de Canaán (4, 1-2). Ante el horror de la opresión, el narrador menciona el

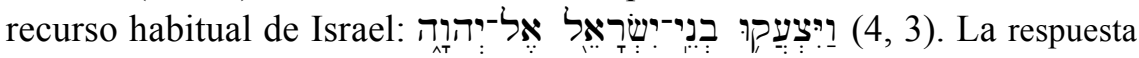
no se hace esperar. Por medio de Débora, YHVH anuncia a Barac que ha puesto en sus manos al enemigo $(4,6){ }^{47}$

Sísara, el jefe del ejército cananeo, es informado acerca del

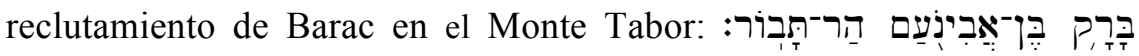

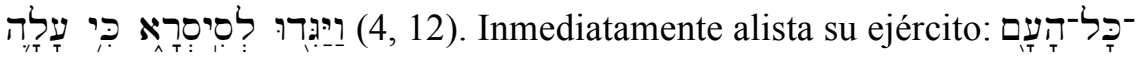

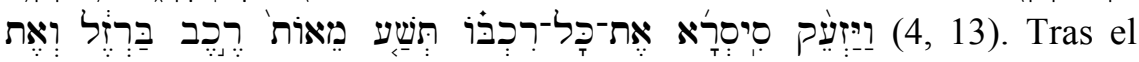
anuncio de victoria asegurada, por parte de Débora $(4,14)$, YHVH

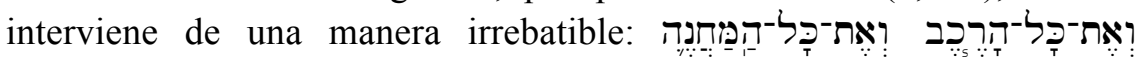

${ }^{44}$ No obstante, la intervención divina no parece directa sino que es más bien concomitante con la tarea humana: “... me salvó de todos los asaltos y me hizo triunfar sobre todos mis enemigos". Tomado de J.-L. SKA, Los enigmas del pasado. Historia de Israel y relato bíblico. Estella, Verbo Divino, 2009, p. 102.

${ }^{45}$ Cf. T. RÖMER, The So-Called Deuteronomistic History. pp. 83-86. 90. No obstante, cabe aclarar que en los capítulos 13-19 en su forma actual se encuentra material tardío.

${ }^{46}$ T. RÖMER, The So-Called Deuteronomistic History. pp. 86-87.

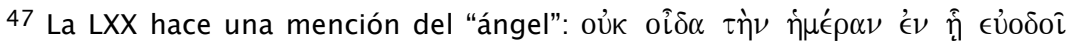

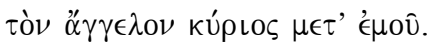


(14, 5). Consecuencia de ella es la fuga, fruto exclusivo del pánico sembrado por $\mathrm{YHVH}$, aun antes del enfrentamiento (14, 15b). Los diez mil hombres de Barac no tendrán más que "עַר־ אֶחד: :completar" la derrota ya causada por la intervención divina (1, 16c). Al relato (Jue 4), sigue un cántico (Jue 5). En este último encontramos una imagen análoga al relato del Éxodo: las aguas del torrente Quisón barren el ejército de Sísara (Jue 5, 19-21). A juicio de Couroyer, es el paralelo más cercano. ${ }^{48}$

Es discutido si ha habido una colección predeuteronomista de tradiciones en la sección Jue 3-9. De todos modos, un trabajo deuteronomístico es perceptible a través del esquema pecado $(3,12 ; 4,1$; $6,1 \mathrm{a} ; 10,6)$, entrega a merced de los enemigos $(3,12-14 ; 4,2 ; 6,1 \mathrm{~b} ; 10$, $7-9)$, grito a $\mathrm{YHVH}(3,15 ; 4,3 ; 6,7 ; 10,10)$, surgimiento de un salvador $(3,9.15)$, derrota del enemigo $(3,30 \mathrm{a} ; 4,23 ; 8,28)$ y paz del país $(3,30$; $5,31 \mathrm{~b} ; 8,28){ }^{49}$

El binomio "pecado-castigo" en relación a Israel no se encuentra en Ex 14. Desde las primeras páginas del libro aparece como víctima de la opresión egipcia. La analogía se encuentra al interno de la descripción de la salvación: intervención fulminante y fuga ante el enemigo, ante un Israel pasivo.

\subsection{La derrota de los filisteos por intercesión de Samuel (1 Sm 7, 2-13)}

Tras la instalación del arca en Quiryat Yearim y la decisión de Israel de servir solamente a YHVH $(7,2.4)$, se desata la opresión filistea de Israel, reunido en Mispá. Los israelitas, al enterarse, caen presa del

${ }^{48}$ B. COUROYER, «L'EXode et la bataille de Qadesh» en RB 97 (1990), p. 328. Su propuesta de una "coloración egipcia" del relato de Ex 14 (inspirado en la batalla de Ramsés II contra los hititas en Qadesh sobre el Orontes), no parece haber ganado consenso entre los exégetas. En todo caso, podría limitarse sólo al relato más antiguo de Ex 14. Cf. J. LOZA VeRA, «Exode 13, $17-14,31$ et la Bataille de Qadesh», en M. SIGRIST (ed,) Études égyptologiques et bibliques à la mémoire du Père B. Couroyer CRB 36, (1997), pp. 29-42. Este último autor deja transparentar sus reparos a la escasa atención diacrónica del homenajeado en su estudio sobre la perícopa.

${ }^{49}$ Cf. G. HenTSChEL, «Das Buch der Richter», en Hrsg. E. ZenGer u.a. Einleitung in das Alte Testament, pp. 218-219 


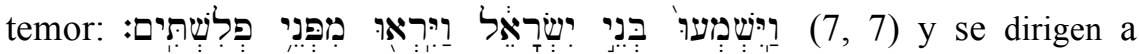
Samuel para que interceda ante YHVH y los salve de la mano de los filisteos $(7,8)$. A la ofrenda sacrificial de Samuel se siguen la escucha y la intervención divinas $(7,9)$. Los acontecimientos se precipitan rápidamente $(7,10)$ :

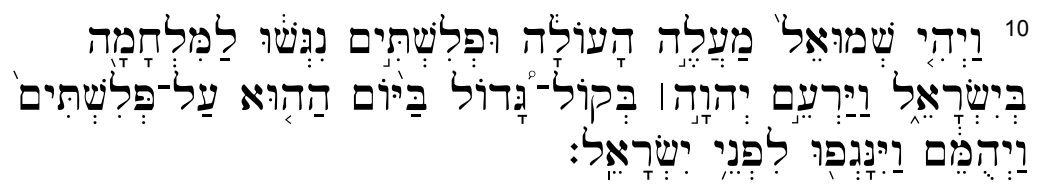

Nos encontramos con un texto que refleja ideas análogas a la intervención divina más antigua descripta en Ex 14. "Eine ähnliche Vorstellung des kriegerischen Eingreifens JHWHs bezeugt 1 Sam 7, 10 , 50

YHVH se sirve del trueno, ${ }^{51}$ un elemento natural, y provoca el pánico y la confusión del enemigo. La acción es rotunda e Israel asiste como espectador al espectáculo de la derrota del enemigo. A esta acción contundente se sigue la fuga de los filisteos y la posterior persecución de Israel del enemigo ya vencido.

Es importante destacar que Samuel ejerce un rol de mediación. La naturaleza profética de este rol insinúa, en opinión de Römer, que subyace aquí la concepción de la palabra profética como medio para conocer la voluntad divina, en sustitución del Templo. Ello permite ubicarnos en la teología deuteronomista del período del exilio o del postexilio. ${ }^{52}$ Por otra parte, el texto podría ser interpretado dentro de la corriente de crítica a la realeza: "Er demonstriert als Richter Israels auch, dass man die Philister ohne einen König vernichtend schlagen könne." ${ }^{53} \mathrm{Si}$ ello es así, nos encontraríamos en un contexto diverso de aquél descripto por Römer a propósito de Jos 10 pero ambos deudores de una misma idea teológica: el protagonismo absoluto de YHVH y su

${ }^{50}$ C. BERnER, Die Exoduserzählung. p. 347. n. 20.

${ }^{51}$ La voz de Dios es normalmente el trueno: Ex 9, 28; Is 30, 30s; Jr 10, 13; 51 , 16; Ez 1, 24; Sal 29; 46, 7; 68, 34; 104, 7; Jb 37, 4.

${ }^{52}$ Cf. T. RÖMER, The So-Called Deuteronomistic History. p. 94; G. HENTSCHEL, “Die Samuelbücher", en Hrsg. E. ZenGER u.a. Einleitung in das Alte Testament 20087, pp. 236-237.

${ }^{53}$ G. HENTSCHEL, «Die Samuelbücher». p. 237. 
acción fulminante delante de los enemigos de Israel.

\subsection{La victoria de adián (Jos 7, 1-25)}

Un texto ulterior que presenta una intervención decisiva de YHVH contra los enemigos de su pueblo es la victoria de Madián. El relato muestra desemejanzas con los pasajes analizados hasta aquí: Israel no aparece del todo pasivo en el momento previo a la derrota. Tras el presagio de victoria (Jos 7, 9-15), Gedeón actúa inteligentemente dividiendo su ejército y "atacando" por sorpresa durante la noche (Jos 7, 19-20). Hay un trabajo estratégico de preparación. Sin embargo, el relato no deja de resaltar la centralidad de YHVH en la victoria: la drástica reducción del ejército de Gedeón tiene la finalidad de dejar en claro a quien se debe el éxito. Ello está explícitamente mencionado (Jos 7, 2):

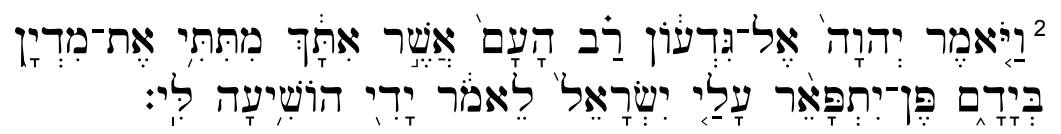

Por otra parte, el narrador menciona que los trescientos hombres no

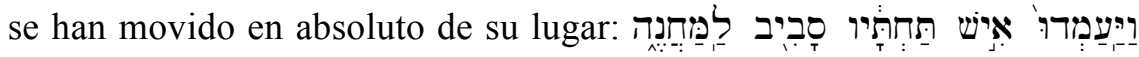
$(7,21)$. A esta intervención meramente "sonora" se sigue la fuga del campamento y la instigación de YHVH a la matanza recíproca de los enemigos. "Tatsächlich ist es JHWH, der eine Panik unter den Midianitern auslöst (7, 13.14.22). "54 Israel no tiene que luchar y posteriormente sólo tendrá que completar el triunfo con la persecución de Madián.

Esta victoria se convirtió en una experiencia célebre y casi

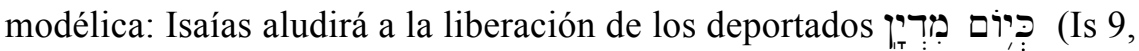
3), Habacuc la menciona para cantar el combate de YHVH (Hab 3, 7) y el salmista pide la salvación contra los enemigos, poniendo a Madián como ejemplo (Sal 83, 10).

En opinión de Berner, el relato de Éxodo 14 tiene relación con la huída de Moisés a Madián:

${ }^{54}$ G. HENTSCHEL, «Das Buch der Richter». p. 215. 
Die Exoduserzählung erweist sich schon in ihre ältesten erreichbaren Bestand als ein literarisches Konstrukt, das von den aufeinander bezogenen Erzählungstücken in Ex $2 * ; 14^{*}$ getragen wird. In der Erzählung von Moses wunderbarer Errettung aus dem Schilf am Ufer des Nils (2, 1.2a.3*.5ab.6a.10ab) und der Flucht des bereits Herangewachsenen nach Midian $(2,11.12 .15 a b 1)$ deutet sich schon das Geschick der Israeliten an, die von JHWH nach ihrer Flucht aus Ägypten am Schilfmeer von ihren ägyptischen Verfolgern errettet werden $(13,20$. $21 a^{*} ; 14,5$ a. 6. 10b. 13a. 14. 19b. 20ab. $21^{\text {a }}$ 2b. 24ab. 25b. 27a2. 30; 15, 22). 55

Si esta vinculación es factible, no sería extraño que hubiese algún tipo de relación, al menos remota, entre la teología del relato de Ex 14 y esta batalla célebre. De allí a la comparación explícita en el paralelismo del oráculo contra Asiria no hay más que un paso (Is 10, 26): ${ }^{56}$

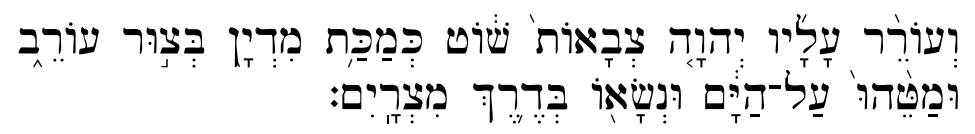

\section{La finalidad del relato antiguo}

Los textos que hemos emparentado con el relato antiguo de Ex 14 (2) contienen en gran medida signos de elaboración deuteronomista. De allí que, extremando estas semejanzas, se haya hecho frecuente hablar de un relato de "guerra santa" de estilo deuteronomista en lo que fue la versión más antigua del relato del mar de Suf. ${ }^{57}$

Según Vervenne, sin embargo, "l'analyse minutieuse de Ska montre à suffisance qu'il n'y a pas d'arguments sérieux, ni formels, ni sur le plan du contenu, pour soutenir la thèse d'un substrat dt/dtr, au sens strict des termes, en Ex. xiii 17 - xiv 31", ${ }^{58}$

55 Cf. C. BERnER, Die Exoduserzählung. p. 430.

56 El oráculo de Is $10,24-27$ ha atribuido a una redacción josiana del siglo VII o a un editor postexílico. Cf. B.S. CHILDS, Isaiah. A Commentary. London - Louisville, OTL, 2000, p. 93. Cf. también Jue 10, 11.

57 Para esta problemática, cf. J.-L. SKA, «Exode xiv contient-il un récit de ‘guerre sainte' de style deutéronomiste?». pp. 454-467.

58 M. VERVENNE, «Le récit de la mer (Exode XIII 17-XIV 31) reflète-t-il une rédaction de type deutéronomique? Quelques remarques sur le problème de l'identification des éléments deutéronomiques contenus dans le Tétrateuque», VTS 66 (1997), p. 375. 
Consecuencia casi necesaria de este diverso género literario es la diferencia de finalidad perseguida: el relato original de Ex 14 no se proponía describir una batalla de YHVH o una victoria fulminante del Dios que los saca de Egipto.

Un análisis del final del relato antiguo (Ex 14, 30-31), según la reconstrucción propuesta, nos permite acercarnos a una explicación

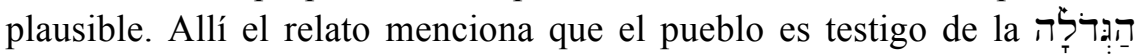
הָיריד con la que YHVH lleva a cabo la liberación definitiva del enemigo opresor

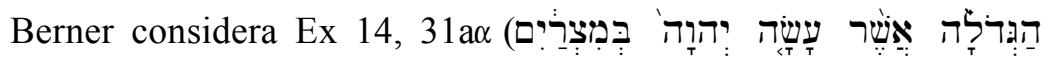
como una añadidura tardía: ello se percibe, a su

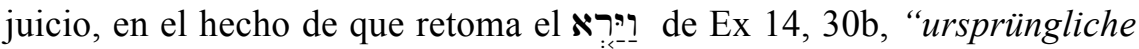
Ende des vorpriesterschriflichen Meerwunderberichts" y en que se encuentra en un nivel literario diverso al contexto siguiente que cambia

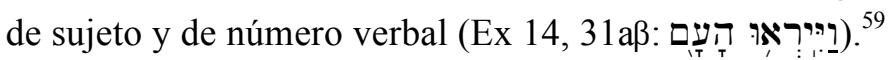

Da 14, 31a ohne die in 14, 31ab geschilderte Reaktion der Israeliten ins Leere läuft, diese hingegen nahtlos an 14, 30 anschließt, ist 14, 31 aa als jüngster Zusatz zum Resümee des Meerwunderberichts zu beurteilen. 60

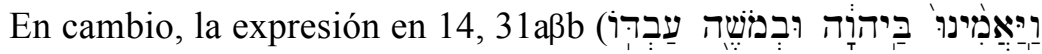

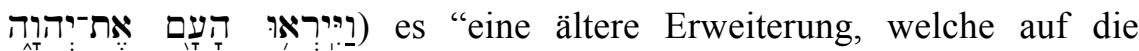
Augenzeugenschaft der Israeliten $(14,30)$ mit Gottesfurch und Glauben nachträglich eine adäquate Reaktion folgen läßt“". ${ }^{61}$

Obviamente que no podemos descartar esta posibilidad. No obstante, no estamos seguros de poder conceder un valor concluyente a estos fundamentos argüidos. Más bien podemos preguntarnos si el relato original podría arribar a una conclusión suficiente con la mera

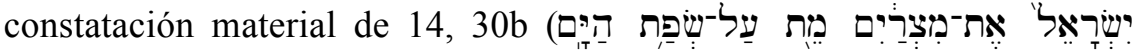
איר:-1).

En Ex 14, 10 el autor había mencionado la reacción de Israel ante

59 Cf. C. BERnER, Die Exoduserzählung. p. 382.

60 Cf. C. BERnER, Die Exoduserzählung. p. 382.

61 Incluso algunos exégetas distinguen estratos diversos entre el "temer" y el "creer". Cf. P. WEIMAR, Die Meerwunderzählung. Eine Redaktionskritische Analyse von Ex 13,17-14,31 (Ägypten und Altes Testament 009; Wiesbaden 1985), p. 274. 


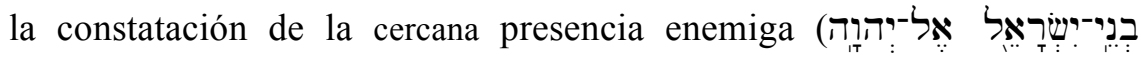

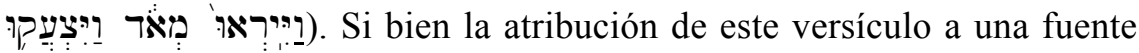
particular es más que compleja, ${ }^{62}$ no obstante es necesario conjeturar razonablemente una reacción por parte del pueblo en el relato antiguo que justifique e introduzca la respuesta de Moisés (Ex 14, 13-14). La

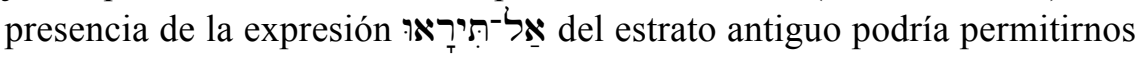

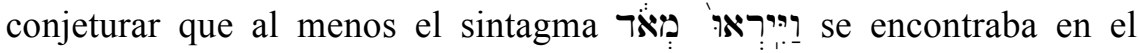
relato antiguo.

Moisés había anunciado la salvación que YHVH cumpliría y su intervención contundente a favor del pueblo. Esta centralidad del accionar divino no quedaría suficientemente puesto de relieve si el relato antiguo hubiese concluido con la mera constatación material del deceso del enemigo en las aguas del mar. El discurso de Moisés al pueblo no estaría seguido por una fórmula de cumplimiento simétrica. La lógica del relato, además de las numerosas semejanzas de vocabulario, sugiere que en Ex 14, 30-31 hayamos de ver el cumplimiento de la anunciado por Moisés en Ex 14, 13-14 y, al menos en muchos de sus elementos, debamos atribuirlo al relato antiguo.

Uno de los elementos importantes que aparece en esta conclusión es el temor de YHVH que nace en el pueblo tras la constatación de la

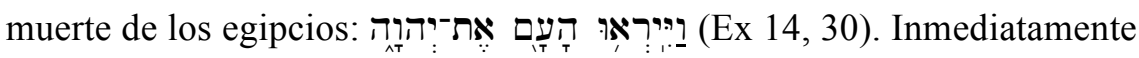
salta a la vista el hecho de nos encontramos con el mismo sujeto y el mismo número verbal que en Ex 14, 13. Si bien no es un argumento sólido, al menos puede ser un indicio plausible que nos permita hermanarlos en la misma fuente. Al temor del pueblo ante el enemigo, tras la intervención divina decisiva, se sigue el temor a YHVH que ha sido el único protagonista del acontecimiento. ${ }^{63}$ Así asistimos a una coherente progresión:

...il faut nettement distinguer les trois étapes que le récit fait franchir à Israël : de la crainte devant l'Egypte (v.10), il passe par la négation de cette crainte (discours de Moïse - v. 13) pour aboutir à la crainte de YHWH au v. 31. Ce qui se passe au cours de ces trois étapes est d'une importance capital pour la compréhension de ce concept qui oscille entre l'épouvante et la vénération. ${ }^{64}$

62 Cf. Sopra, n. 14.

63 Cf. J.-L. SKA, Le passage de la mer. p. 136.

64 J.-L. SKA, Le passage de la mer. p. 137. 
En el libro del Éxodo el temor de YHVH es un motivo ya introducido: es la actitud de las parteras ante el pedido arbitrario del faraón de asesinar a los varones (Ex 1, 17. 21). Allí se habla de temer a . הארלה Para Berner, la perícopa de las parteras ha de considerarse como "die älteste Erweiterung des vorpriesterschriftlichen Grundbestandes von Ex". ${ }^{65}$ J. C. Gertz, en cambio, ubica la perícopa de las parteras en el estadio más antiguo. ${ }^{66} \mathrm{Sin}$ desconocer los rastros de una reelaboración, el autor considera Ex 1, 15-20a.21b como atribuible al "Grundbestand der Hebammenepisode". ${ }^{67}$ En todo caso, nos encontramos con material no sacerdotal.

El temor será también la reacción de Moisés ante la teofanía de la zarza. Situándose desde el punto de vista de Moisés, el narrador referirá

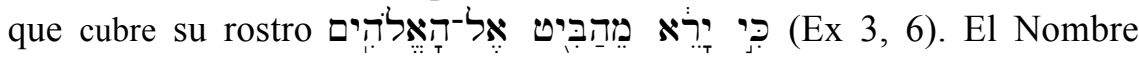
divino aún no le ha sido revelado. En un minucioso análisis, Berner consideraba la reacción de temor por parte de Moisés como perteneciente al estadio más antiguo de este relato. ${ }^{68}$

Estos dos ejemplos nos permiten al menos conjeturar que el temor de YHVH que se menciona en Ex 14, 31 puede legítimamente ser atribuido al relato antiguo de la salvación junto al mar. En el desenlace de la historia de opresión iniciada en Ex 1, el pueblo deja de lado el miedo ante el enemigo y se deja invadir por el temor de YHVH, el mismo espíritu reverencial que en el relato de la vocación de Moisés, había llenado al mediador de la liberación. ${ }^{69}$

65 C. BERNER, Die Exoduserzählung. p. 27. Así el autor la sitúa en un nivel semejante a Ex 14, 14, 31abb que considera como una "ältere Erweiterung". J. C. GerTz, en cambio, ubica la perícopa de las parteras en el estadio más antiguo. ID., Tradition. p. 350.

66 J. C. GerTZ, Tradition. p. 350.

67 J. C. GeRTZ, Tradition. p. 373.

68 Cf. C. BERNER, Die Exoduserzählung. pp. 71-74. Existen, no obstante, otros textos donde aparece el motivo del temor, pero que no tienen relación con el relato antiguo: a pesar de la "conversión" del faraón tras la séptima plaga, Moisés declara

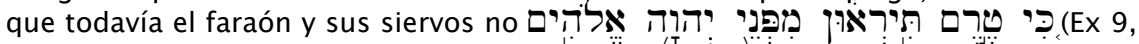
30). Nunca se dirá que lo hayan hecho. El cánitico de María tras la salvación junto al mar expresa lo terrible de las obras de YHVH (Ex 15, 11) y el pueblo, tras la renovación de la Alianza, deberá constatar asimismo lo terrible de su obrar (Ex 30, 10).

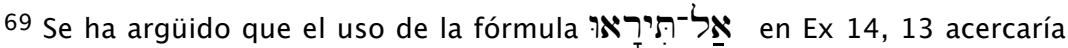
el relato a la escuela deuteronomista. La tesis no resiste ā un análisis crítico. Cf. J.- 
Sin embargo, no termina aquí la finalidad del relato antiguo. No se trata sólo de una descripción de una actitud del pueblo en relación al protagonista indudable de su historia. El texto formula además una actitud del pueblo en relación al mediador de esta intervención divina en su historia.

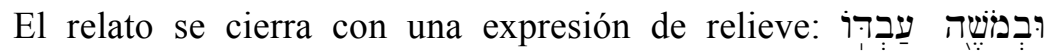

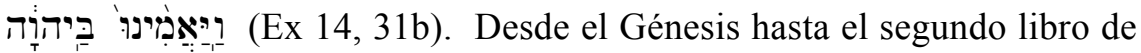
los Reyes el hif'il del verbo אמי se refiere en su gran mayoría a Dios. ${ }^{70}$ En el libro del Éxodo contamos con tres excepciones a esta "regla".

La primera de ellas la encontramos en el relato de la vocación de

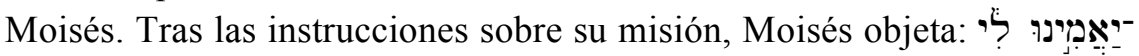
לא. (Ex 4, 1). Los prodigios que YHVH le concede realizar a Moisés

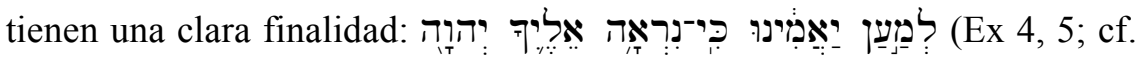
4, 8-9). El contexto para la cuestión de la credibilidad de Moisés ya está creado.

El otro texto en el que aparece el verbo con una referencia a Moisés es el relato de la Alianza en el Sinaí. YHVH se acerca en una densa nube porque quiere hacer que el pueblo escuche su conversación con el mediador. Ello tiene una finalidad bien precisa: !ִ (Ex 19, 9). En opinión de Berner, "hat das Glaubensmotiv im Exodusbuch eine Entwicklung durchlaufen” cuyo „Endpunkt“ lo constituye Ex 19, 9. ${ }^{71}$

Con respecto a la relación entre el Glaubensmotiv de Ex 4 y de Ex 14, el exégeta concede prioridad literaria a la formulación del relato junto al mar:

Da nun mit dem Glauben des Volkes an Mose (4, 1-9*.30b.31a) in ausführlicher Weise ein Teilaspekt der Doppelnotiz aus 14, 31abb vertieft wird, der überdies - sieht man von 19,9a ab - inneralttestamentlich ohne weitere Parallele ist, legt es sich nahe, daß der Aussage in 14,31ab literarische Priorität zukommt. ${ }^{72}$

L. SKA, «Exode xiv contient-il un récit de 'guerre sainte' de style deutéronomiste?», pp. $458-459$.

70 Cf. C. BERnER, Die Exoduserzählung, p. 383.

71 Cf. C. BERnER, Die Exoduserzählung, p. 383. nuestro.

72 C. BERNER, Die Exoduserzählung, p. 384. Lo destacado con cursiva es 
Lejos de pretender resolver la cuestión, cabría preguntarse en qué sentido puede decirse que Ex 4, 4, 1-9*.30b.31a profundiza un aspecto de Ex 14, 31ab. No estamos seguros de que la mera provisión de signos (bastón convertido en serpiente, la mano cubierta de lepra o el agua convertida en sangre) pueda ser una respuesta. Estos signos han podido servir para una acreditación inicial que sin embargo será puesta en cuestión por las sucesivas complicaciones de los acontecimientos del relato. Sólo la constatación de una liberación definitiva de Egipto permitirá arribar una fe más firme y acrisolada. De hecho, la construcción de אמן con la preposición a diferencia de la formulación con ל? de Ex 4, evidencia una actitud consolidada:

En conséquence, Ex 14, 31 décrit la relation de confiance qui unit désormais (jusqu'à preuve du contraire) Israël à YHWH et à Moïse, alors qu'Ex 4, 31 n'allait pas si loin: le peuple se contenait de donner son accord, sans que sa personne soit complètement engagée. La confiance d'Ex 14, 31 est passée par le creuset du doute et du découragement, elle a été forgée au cours des épreuves. Israël a dû surmonter sa défiance et sa terrible déception initiale $(5,20-21)$. Le haut-fait de Dieu (hayyäd haGGedölâ - 14, 30 [sic !]) a obtenu ce que les signes de 4, 30 n'avaient pu atteindre. Ex 14 décrit les ultimes étapes de ce processus. ${ }^{73}$

Consideramos entonces que Ex 14, 31 evidencia un punto de llegada de la historia comenzada junto a la zarza y, a la vez, el punto de llegada o finalidad del relato antiguo de la salvación junto al mar. Es el momento culminante no sólo de la liberación del pueblo de sus primeros opresores sino también del camino de fe en YHVH y de acreditación de Moisés como su mediador.

A diferencia de los relatos de guerra santa donde la fe es presupuesto inicial, aquí la fe es punto de llegada. ${ }^{74}$

Esta fe tiene por objeto casi simétricamente a יהוה y a פמשֶֶה a quien

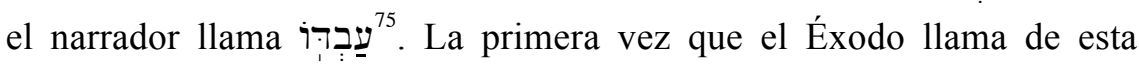
manera a Moisés, por medio de sus mismos labios, es en 4, 10. Allí

73 J.-L. SKA, Le passage de la mer, p. 144. En lugar de 14, 30 debe la cita se encuentra en 14, 31 .

74 Cf. J.-L. SKA, «Exode xiv contient-il un récit de 'guerre sainte' de style deutéronomiste?», pp. 455. 457.

75 J.-L. SKA admite que pueda tratarse de una añadidura deuteronomista al final del relato. No obstante no puede excluirse que sea antiguo. Cf. ID., «Exode xiv contient-il un récit de 'guerre sainte' de style deutéronomiste?», p. 463. 
objetaba la misión encomendada debido a su insuficiencia personal. Ahora el pueblo lo hace objeto de su confianza. YHVH mismo ha

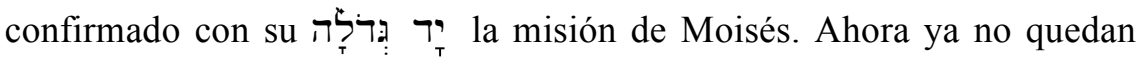
dudas de que su pretensión de conducción tienen un origen divino.

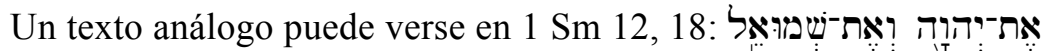

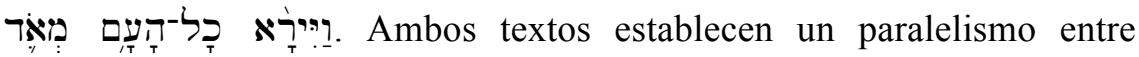
YHVH y un mediador y tienen una finalidad análoga:

La foi en Dieu est aussi foi en Moïse, la crainte de Dieu signifie aussi crainte de Samuel (...) Les faits racontés veulent fonder le pouvoir évocateur et l'autorité de ces personnages et des institutions qui s'en réclament (...). On se rend compte, après cela, qu'il est difficile d'admettre que le récit d'Ex. xiv soit un simple récit de "guerre sainte». II ne veut pas seulement raconter comment Dieu a assisté son peuple dans une lutte inégale, il veut éveiller la foi en Dieu et en Moïse. On dirait presque : éveiller la foi en ce Dieu qui se révèle par Moïse. ${ }^{76}$

Resumiendo: el "ver" a sus temidos perseguidores muertos a orillas del mar (Ex 14, 30) suscita en el pueblo el "temor" y la "fe". " $L a$ sequenza 'vedere' - 'temere' - 'credere' forma la struttura basilare della conclusione del racconto $\mathrm{Je}$ ". ${ }^{77} \mathrm{De}$ esta forma, aceptando la pertenencia de Ex 14, 30-31 al relato antiguo de la liberación junto al mar, su formulación casi solemne deja en claro que se trata de un punto sobre el que pretende insistir y sobre el que recae la intención del autor. Con los eventos de Ex 14 no sólo culmina el drama de la opresión del pueblo por parte de los egipcios sino también se arriba a un hito en el camino de fe de un pueblo para quien hasta ahora YHVH y Moisés eran nombres prácticamente extraños.

\section{Ecos del milagro del mar}

Es innegable que la redacción final del relato ha hecho fortuna en la recepción bíblica. Varios textos dan prueba de ello (Nm 33, 8; Neh 9, 9-11; Sal 78, 12-13. 43-51; 106, 7-12; 136, 10; Is 10, 26). Con mucha probabilidad, la fuente de inspiración para el relato sacerdotal ha sido la

76 Cf. J.-L. SKA, «Exode xiv contient-il un récit de 'guerre sainte' de style deutéronomiste?», p. 458.

77 J.-L. SKA, II Passaggio del Mare (Es 14-15). Ad usum privatum tantum, Roma, 2003, p. 41. 
narración del paso del río Jordán (Jos $3,13.16),{ }^{78}$ un texto posiblemente preexílico. ${ }^{79}$ Normalmente "no se presta más que a los ricos": ${ }^{80}$ la experiencia de la salida de Egipto - "das narrative Herzstück des Hexateuch" ${ }^{81}$ no podría pasar a la historia con prodigios menos espectaculares que los de la entrada en la Tierra prometida. La salida de Egipto y la entrada en Canaán están marcados por la misma envergadura de prodigio, en una inclusio brillante que el hagiógrafo legó a la historia de Israel.

Nuestro objetivo en esta última parte, luego de haber rastreado algunas analogías literarias con el relato más antiguo, es verificar si esta primera historia de liberación ha dejado huellas en el Hexateuco. ${ }^{82}$

\subsection{Alusiones al milagro del mar en la Torah}

En el resto del libro del Éxodo, cuando se alude a la salida de Egipto, no se precisa la naturaleza de la acción salvífica: ni el viento que seca el mar y se vuelve contra Egipto ni mucho menos se habla del milagroso paso por medio del mar. En su mayoría, se trata de fugaces referencias. $^{83}$

Tampoco el libro del Levítico contiene alguna referencia concreta

78 Cf. J. A. WAGENAAR, «Crossing the Sea of Reeds (Ex 13-14) and the Jordan (Josh 3-4). A Priestly Framework for the Wilderness Wandering», en BEThL 126; (1996), pp. 461-470. Citado en C. BERNER, Die Exoduserzählung. p. 364, n. 86; “...it seems highly probable that the language of the Reed Sea was influenced by the Jordan tradition of the river's crossing which introduced the language of a path through the sea and the river's stoppage. Thus the exodus as the 'going out of Egypt' and the conquest as the 'coming into the land' were joined in a cultic celebration of Israel's deliverance and transmitted together": B. CHILDS, The Book of Exodus. A Critical, Theological Commentary. London, OTL, 1974, p. 223.

79 "Nach K. Bieberstein ähneln die frühen Fassungen des Durchzugs durch den Jordan (3, 1.5.13b-14a.16) und der Eroberung Jerichos (6, 1-3.4b-5.11.1415.20c-21) einander in Struktur und Ziel und weisen eine gemeinsame vorexilische Bearbeitung auf": G. HENTSCHEL, "Das Buch Josua", Einleitung in das Alte Testament (Hrsg. E. ZENGER u.a.), 206.

80 J.-L. SKA, Los enigmas del pasado. p. 94.

81 C. BERNER, Die Exoduserzählung. p.1.

82 No usamos la expresión en el sentido estricto, a nivel literario, sino desde un punto de vista sincrónico: con el libro de Josué culmina la historia de un pueblo sin tierra.

83 Cf. Ex 16, 1. 6. 32; 18, 1. 8 ss; 19,$4 ; 20,2 ; 23,15 ; 29,46 ; 32,1.4 .7-11$. $23 ; 33,1 ; 34,18$. 
sobre la naturaleza del acontecimiento ${ }^{84}$ mientras que el libro de los Números, de entre todas las alusiones genéricas a la salida de Egipto, ${ }^{85}$

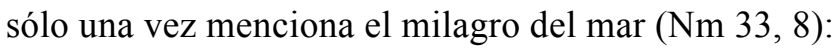

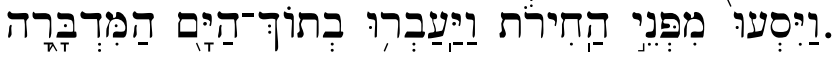

La afirmación se encuentra en la tercera sección del libro. ${ }^{86}$ No añade ninguna descripción particular. Sin embargo, el uso de la expresión deja en evidencia que el autor supone un paso. Es la primera referencia explícita de la Torah, fuera del relato final de Ex 14, a un camino abierto en medio del mar. Sin embargo, muchos exégetas sostienen que la mayor parte de los textos de esta tercera sección han de datarse durante el exilio o después de él. ${ }^{87}$

En el libro del Deuteronomio, Moisés recuerda al pueblo temeroso que Dios "lucharía por ellos" como lo hizo en Egipto (Dt 1, 30). La fórmula parece retomar las palabras del discurso de Moisés al pueblo, en el relato más antiguo $\left(\right.$ Ex 14, 14.25). ${ }^{88}$

Por otra parte, de entre todas las demás alusiones a la salida, ${ }^{89}$ hay una particularmente importante: el recuerdo de la salida en Egipto en el segundo discurso mosaico (Dt 11, 2-4):

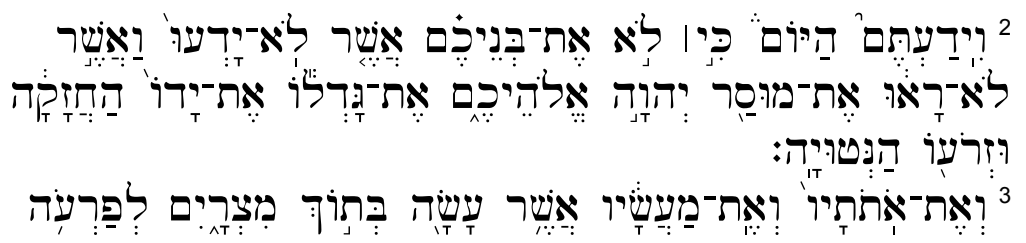

${ }^{84}$ Cf. Lv 11,$45 ; 19,36 ; 22,33 ; 23,43 ; 25,38.42 .55 ; 26: 13,45$.

85 Cf. Nm 1,$1 ; 3,13 ; 8,17 ; 9,1 ; 14,13.22 ; 15,41 ; 20,15-16 ; 22,5.11 ; 23$, $22 ; 24,8 ; 33,1$ ss.

86 Cf. F. García López, El Pentateuco. p. 242. El autor divide en tres partes: a) En el desierto del Sinaí, con los preparativos para la marcha $(1,1-10,10)$; b) Desde el desierto hasta la estepa de Moab $(10,11-21,35)$ y c) En la estepa de Moab (2236).

87 Cf. V. FRITZ, Die Entstehung Israels im 12. und 11. Jahrhundert v. Chr. en BE 2 (1996), p. 21. Citado en F. GARCía LóPEZ, El Pentateuco. p. 261.

88 Una exposición más detallada de la expresión puede verse en M. VERVENNE, «Le récit de la mer». pp. 377-379.

89 Dt 4,20. 34-37. 5, 6. 15; 6, 12. 21ss; 7, 8. 15. 18; 8, 14; 9, 7. 12. 26; 16, 1.3.6. $12 ; 20,1 ; 26,7-8 ; 29,1.24 ; 34,11$. 


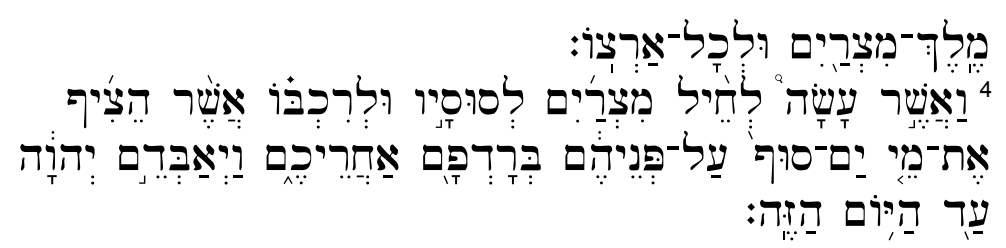

El texto recuerda los signos y las obras realizadas por YHVH

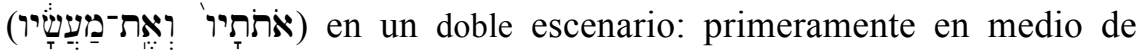
Egipto, contra el Faraón y contra el pueblo, aludiendo a las plagas con las que Dios ha herido al opresor. En segundo lugar, el texto hace referencia al escenario del mar: allí interviene YHVH específicamente contra su ejército, sus caballos y carros. La naturaleza de la acción es descripta con el hif'il del verbo צצ: en medio del mar YHVH hizo precipitar las aguas sobre los perseguidores.

El texto brilla por su concisión, sin abundar en detalles; no

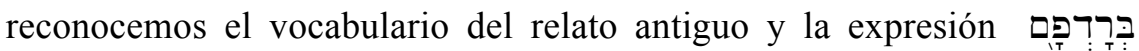
podría sugerir más bien la trama del relato sacerdotal: las aguas caen sobre el ejército mientras están persiguiendo a Israel. No obstante, sería posible entender el sintagma del mar, sino a la persecución previa y que ocasiona el temor del pueblo (Ex 14,9). Nos encontramos probablemente con un texto tardío:

The major part of Deut. 11 belongs to a late stage of editing. This chapter is like a patchwork combining themes from other chapters of Deuteronomy (...). The beginning of the chapter (vv. 2-9), which presupposes the account of Num. 16, could hardly have been composed before the Persian period. 90

Por otra parte, si asumimos con Ska que el relato de la liberación junto al mar de Suf no parece conocer el ciclo de las plagas, ${ }^{91}$ entonces la vinculación entre ambos relatos que hace Dt 11 evidencia un estadio tardío.

\subsection{EI libro de Josué}

Una primera alusión al secamiento de las aguas obrado por YHVH

90 T. RÖMER, The So-Called Deuteronomistic History. p. 175, n. 25.

${ }^{11}$ Cf. J.-L. SKA, Introduction to the reading of the Pentateuch. p. 212. 
la encontramos en labios de Rajab (Jos 2,10):

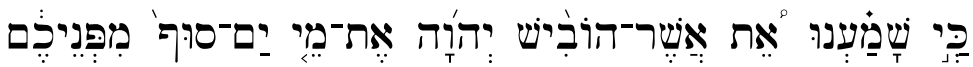

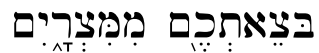

El texto echa mano del verbo יבשי que significa "secar". Con él se alude al secamiento de las aguas después del diluvio (Gn 8,7; 14), la sequía del torrente Querit (1 R 17,7); de las aguas en la naturaleza por intervención divina (Sal 74, 15; Jb 12, 15; 14, 11) o la desecación del Nilo (Is 19, 5). La expresión יבים־ sólo se encuentra aquí y en Dt 11, 4.

Con este texto nos encontramos con una formulación diversa: el

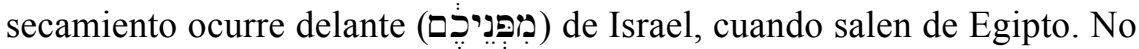
hay ninguna mención de división de aguas ni se precisa que ello ha implicado la destrucción de los egipcios. Sin embargo, es muy probable que el autor tenga ya en mente la idea de un paso de Israel. Ello puede confirmarse con las palabras de Josué cuando erige las doce piedras conmemorativas (Jos 4, 19-24):

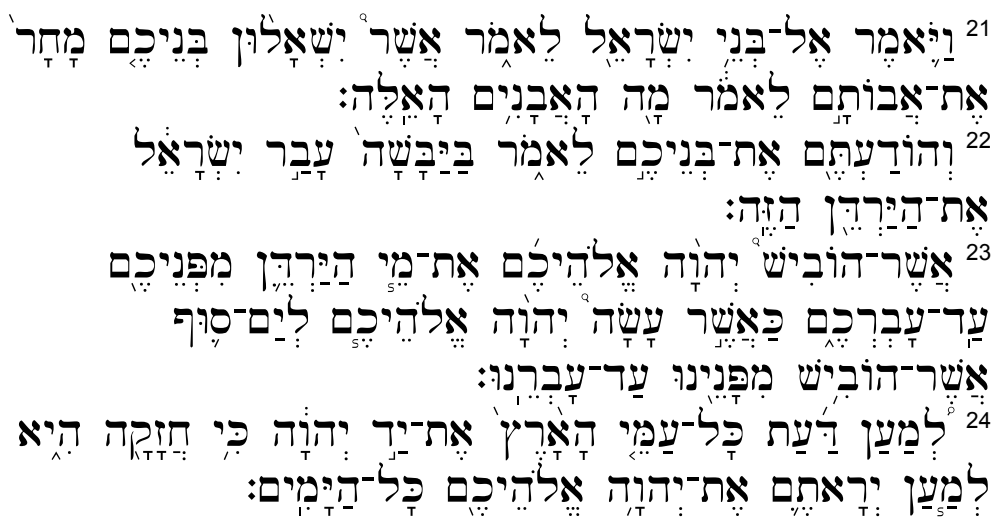

Se trata del primer texto que paragona el paso del Jordán con el del

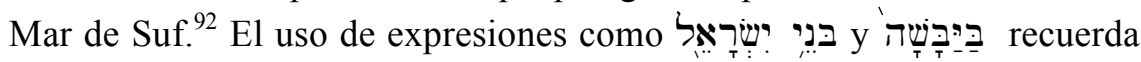
el vocabulario del relato sacerdotal del milagro del mar (Ex 14, 8. 10. 16).

92 Cf. Otro texto: Sal 114. 
Sin embargo, no se menciona una división de aguas ni la destrucción de los egipcios. El punto de interés del autor es el "paso" por medio del mar. Vale decir, nuestro texto evidencia un "paso" de Israel en medio del mar que ha sido "secado", pero no "dividido". ¿Nos encontramos ante una suerte de "tradición mixta", germen del que luego partirá el escritor sacerdotal para agigantar el milagro?

A pesar de esta atestación de un paso por medio del mar de Suf, es llamativo que posteriormente no haya ninguna mención de él en el discurso de Josué en la asamblea de Siquén, en la que el sucesor de Moisés reúne a los ancianos, jefes, jueces y escribas de Israel (Jos 24, 1) y hace memoria allí de la vocación de Israel y de su experiencia en Egipto (24, 4c-7):

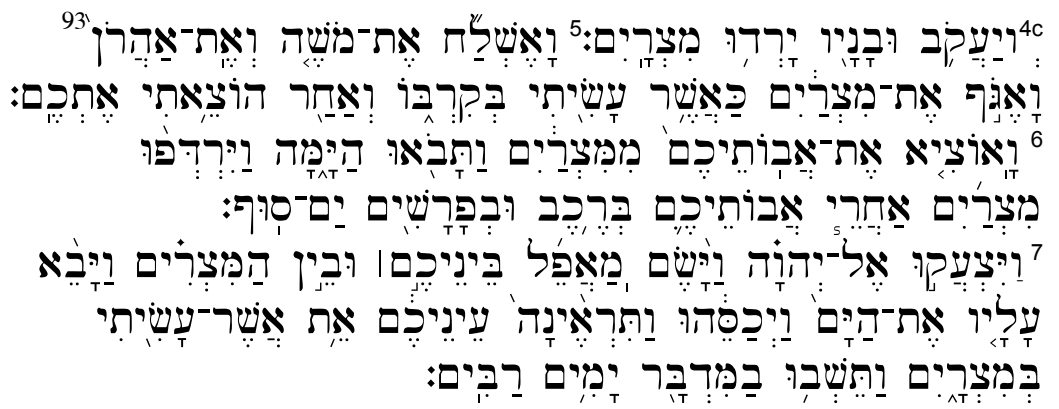

El discurso muestra una semejanza con algunos elementos mencionados en el relato más antiguo: se hace referencia a la salida de Egipto, a la llegada al mar, a la persecución hasta el Mar de Suf por parte de los egipcios, a la oscuridad interpuesta entre ambos campamentos y la acción de hacer volver el mar sobre los egipcios para cubrirlos. Los ojos de Israel han sido testigos de lo obrado por YHVH.

La procedencia literaria de los discursos de los capítulos 1 y $23-24$ se puede vincular a las ediciones deuteronomistas del libro de Josué.

93 Es llamativo que el texto griego omita la mención de Aarón. Sobre la relación entre ambos textos, damos la palabra a G. HENTSCHEL, «Das Buch Josua», Einleitung in das Alte Testament (Hrsg. E. ZeNGER u.a.), p. 203: "Zwischen dem masoretischen Text und der ältesten Fassung der Septuaginta «bestehen erhebliche Divergenzen» (K. Bieberstein). Die alte Septuaginta, die im Josuabuch den Kodex Vaticanus bezeugt wird, ist durchschnittlich 4 oder 5\% kürzer als der hebräische Text, an manchen Stellen allerdings länger. Der kürzere Text kann auf eine frühere Gestalt des Buches zurückgehen (G. Auld)". 
Algunos incluso consideran el capítulo 24 como elaboración posterior, durante el postexilio. ${ }^{94}$

A nuestra previa afirmación sobre la ausencia de la mención de un paso por el mar se plantea un problema: el sentido de la expresión הָיד

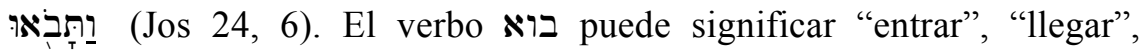
"venir", "acercarse". ¿S5 expresa con ello una entrada al mar o una llegada al mismo? Una simple comparación con otras versiones nos

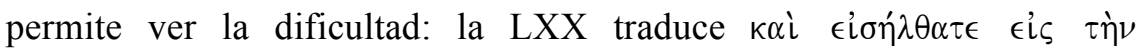
$\theta \alpha \dot{\lambda} \alpha \sigma \sigma \alpha \alpha \nu$ mientras que la Vulgata vierte "et venistis ad mare".

Algunos indicios nos permiten encolumnarnos con Jerónimo. El

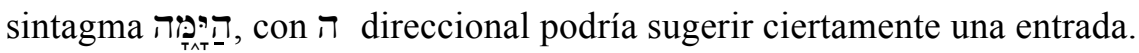

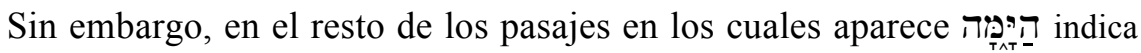
casi siempre límite ${ }^{96}$. Por el contrario, podemos ver que la claridad de la expresión sacerdotal es meridiana cuando se quiere expresar sin lugar a

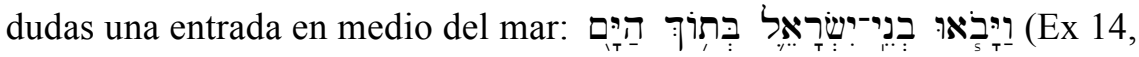
22). No encontramos una claridad semejante en este discurso.

A lo dicho, hemos de agregar que el lugar de la expresión en el texto favorece la interpretación que seguimos: de lo contrario describiría una entrada del pueblo en el mar con la posterior persecución de Egipto y recién después vendría el grito a YHVH y la oscuridad que los separa. Un iter de acontecimientos no rastreable en el texto de Ex 14.

De allí que podamos afirmar con cierta probabilidad que el discurso de Josué, aun cuando contenga cierta terminología que se acerca

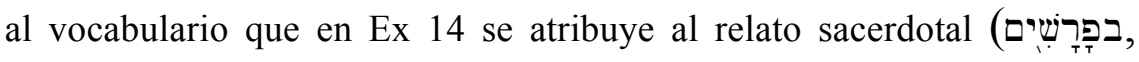

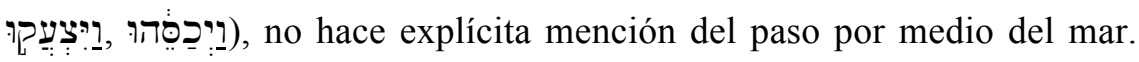
Cuando más adelante aluda al evento del río Jordán no deja lugar a dudas

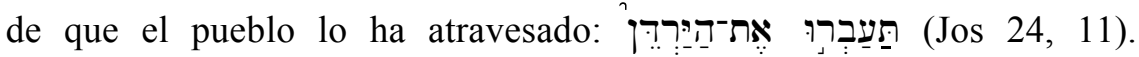
Ciertamente tampoco menciona la acción del viento del este que seca el mar o la intervención de YHVH que infunde pánico en el campamento

94 Cf. T. RÖMER, The So-Called Deuteronomistic History. A sociological, historical and literary introduction, New York, 2007, p. 82; 180-182; V. FRITZ, Das Buch Josua. en HAT I/7 (1994), pp. 235-236.

95 Cf. L. Alonso SCHÖKEL, Diccionario Bíblico Hebreo-Español. Madrid, Trotta 19942, pp. 103-104.

96 Cf. Nm 34, 5; Jos 15,12; 16, 6. 8; 17, 9; 19, 26. 29; sólo en Ez 47, 8 podría indicar una "entrada". 
egipcio. El vocabulario no es el del relato antiguo, pero sí parece reflejar su contenido, al menos en sus elementos fundamentales.

\section{Breves consideraciones conclusivas}

A lo largo de nuestro trabajo hemos mencionado que en el relato antiguo de Ex 14 no hay una relato de guerra santa de estilo deuteronomista. No hay dos ejércitos que combaten. Hay, no obstante, dos adversarios que se enfrentan: el Faraón con su ejército por un lado y YHVH, que defiende a su pueblo, por el otro. Aquél está provisto de carros y caballos. A YHVH no le hacen falta para provocar una derrota fulminante. En este contexto entendemos el alcance del verbo bélico לחם del que se sirve el autor (Ex 14, 14).

Por ello, es cierto que "on ne peut nier le fait que le texte du récit porte l'empreinte d'une tradition présentant des formes et des idées qui ont des points communs avec des textes dt/dtr". ${ }^{97}$ Cabe aclarar que "puntos comunes" no equivale a identidad ideológica. Aceptar eventuales retoques deuteronomistas, como podría ser eventualmente la añadidura del ángel (Ex 14, 19a), no significa asumir un estilo deuteronomista en el relato. En la línea de la "audacieuse inversion" de Vervenne, podríamos decir que no hay que confundir el árbol con el bosque.

Un análisis del final del relato antiguo (Ex 14, 30-31) permite descartar ulteriormente la posibilidad de que un relato de guerra santa esté al origen de Ex 14: ¿por qué se mencionaría a Moisés en un relato que tendría por finalidad exaltar una victoria bélica debida a la exclusiva intervención de YHVH? No hay una confesión semejante en los relatos bélicos de guerra santa. El hecho de que el nombre de Moisés esté presente junto al de YHVH en este relato orienta decisivamente hacia la compresión de su naturaleza: el relato pretende vincular la intervención divina a la figura de Moisés y de esta forma legitimarlo como hombre de Dios ante el pueblo. Creer en YHVH no puede desvincularse de creer en Moisés. Será una preocupación que se repetirá con ocasión de la Alianza (Ex 19, 9).

Ciertamente no podemos afirmar que Ex 14, en su núcleo más

97 M. VERVENNE, «Le récit de la mer». p. 375.

98 M. VERVENNE, «Le récit de la mer». pp. 379-380. 
antiguo, refleje un relato embebido en la corriente deuteronomista en alguna de sus fases. Un análisis detallado y exhaustivo de la cuestión no permite extraer tal consecuencia. Pero posiblemente lo contrario pueda tener una mayor plausibilidad: de manera análoga a la influencia de Ex $14^{*}$ sobre el relato cronista de 2 Cro $20,17,{ }^{99}$ el deuteronomista encontró, no sólo en la ideología asiria, sino también en el núcleo más antiguo de Ex 14, una veta que supo explotar con creces y que quedará testimoniado en algunos relatos épicos de la historia deutoronomista. No sería un fenómeno aislado. ${ }^{100}$ En la Biblia no se crea ex nihilo.

Por otra parte, las alusiones a la salida de Egipto que hemos encontramos en el Hexateuco son numerosas pero fugaces y en la mayoría de los casos no precisan qué acontecimiento suponen junto al mar. Un número considerable de estas alusiones consisten en una Herausführungsformel. Las escasas menciones explícitas de un paso son tardías (Nm 33, 8; Jos 2, 10; 4, 19-24).

Es llamativo que el Deuteronomio, aun en textos tardíos, no sea claro en la descripción de la naturaleza del evento. A nuestro juicio, no se puede descartar que tenga en mente la trama del relato antiguo (Dt 1, 30; 11, 2-4).

Más sorprendente aun es el libro de Josué: junto a las menciones de un paso por medio del mar (Jos 2, 10; 4, 19-24), encontramos un texto importante en el que parece describirse la trama antigua (Jos 24). Si la elaboración de este discurso es postexílica, podría evidenciar la tardía supervivencia independiente de la tradición del relato antiguo. Comparando con las afirmaciones de Jos 2, 10 y 4, 19-24 podríamos hipotetizar que aun cuando ya se encuentre la idea de un paso por medio del mar de Suf, análogo al del Jordán, no se trata de una tradición totalmente impuesta de modo dominante. Lo que en el relato final de Ex 14 aparece ya unido, en el libro de Josué parecería andar aún por carriles paralelos. Nos movemos sin embargo en el campo de las hipótesis apenas posibles. ${ }^{101}$

99 Sobre esta relación entre los dos relatos, cf. J.-L. SKA, «Exode xiv contient-il un récit de 'guerre sainte' de style deutéronomiste?», pp. 456-457.

100 Cf. N. LOHFINK, «Dartstellungskunst und Theologie in Dtn. 1, 6-3, 29», en Bib 41 (1960), pp. 105-134, citado en J.-L. SKA, «Exode xiv contient-il un récit de 'guerre sainte' de style deutéronomiste?», p. 461.

101 En el resto de los libros que conforman la llamada historia deuteronomista también las afirmaciones son genéricas: Jue 2,1. 12; 6, 8-9. 13; 10,11; 1 Sm 2, 27; 
Todo este análisis ha insinuado una cierta relación entre el relato antiguo de Ex 14 y la teología o escuela deuteronomista. Como hemos mencionado, algunos han propuesto ver un relato de tal en la versión más antigua del acontecimiento liberador del mar de Suf. Algunas alusiones a este relato antiguo han subsistido en algunos textos pertenecientes a esta corriente. Sin embargo, lo dicho hasta ahora nos lleva a concebir estas relaciones no como indicios de un relato deuteronomista en los acontecimientos de Ex 14*, sino más bien como ejemplos, en cierto sentido, de su Wirkungsgeschichte intrabíblica.

La experiencia de salvación descripta por esta narración antigua ha continuado ejerciendo su influjo: "Sie ist über Generationen hinweg Gegenstand theologischer Reflexion". ${ }^{102}$ El relato Sacerdotal que ha agigantado el milagro da prueba suficiente de ello. Paulatinamente en el curso de la historia el relato antiguo será cubierto por las aguas de la versión sacerdotal: una tendencia que ya se percibe en la Escritura misma y que terminará imponiéndose en el judaísmo y servirá también al cristianismo primitivo para edificar a los creyentes (1 Co 10, 1-2).

Por otra parte, el relato final de Ex 14 nos brinda un ejemplo significativo del complejo proceso de formación del Pentateuco. En gran medida, la historia de su exégesis refleja la historia de explicación de la formación de la Torah. ${ }^{103} \mathrm{Si}$ es cierto que "un botón basta para muestra", por la complejidad de su exégesis podemos casi entender la conclusión escéptica de Sicre:

\begin{abstract}
Y las investigaciones de los últimos siglos deberían animarnos a abandonar esta temática de los orígenes del Pentateuco. No sabemos a ciencia cierta cómo se formó. Por eso es preferible dedicarse a un tipo de lectura que tenga en cuenta el resultado final, los cinco libros actuales, no el proceso de formación de la obra. No se trata de volver a visiones simplistas, faltas de espíritu crítico, que soslayan las dificultades cerrando los ojos ante ellas. Se trata de aceptar lo irremediable. ${ }^{104}$
\end{abstract}

Sin embargo, a pesar de las importantes diferencias que aún

4, 8; 6, 6 (hace referencia al endurecimiento del corazón); 8, 8; 10, 18; 12, 6- 8; 2 Sm 7, 6. 23; 1 R 8, 9. 16. 21. 51. 53; 9, 9; 12, 28. 2 R 17, 7. 36.

102 J. C. GeRTZ, Tradition, 189.

103 En el relato final se individuaban las fuentes clásicas de la teoría documentaria. Cf. E. ChARPENTIER, Pour lire I'Ancien Testament, Paris, 19839, pp. 26-30; B. CHILDS, The Book of Exodus. pp. 220-221.

104 J. L. SICRE, Introducción al Antiguo Testamento. Estella, Verbo Divino, 2002, p. 88. El énfasis por medio de la cursiva es nuestro. 
subsisten entre los expertos, hay un consenso básico acerca de las manos que han intervenido en la composición de este texto fundamental de la vida de Israel que nos permiten caminar relativamente seguros sobre el mar (cf. Mt 14, 22-30), sin hundirnos en el "comprensible" escepticismo. Los estadios reconocibles en el relato final de Ex 14 nos remiten a complejos procesos análogos en la formación del Pentateuco.

Konsensfähig ist in der gegenwärtigen Pentateuchkritik allein die Unterscheidung zwischen Priesterschrift und nichtpriesterschriftlichem Text geblieben. Dabei setzt sich freilich vermehrt die Erkenntnis durch, dass beträchtliche Teile der letztgenannten Partien nicht vor-, sondern vielmehr nachpriesterschriftlich sind, also in Horizont der redaktionellen Verbindung von $\mathrm{P}$ mit dem vorpriesterschriftlichen Textbestand liegen. 105

Ciertamente no puede hacerse una equiparación total entre la redacción final de Ex 14 y la del Pentateuco. Ésta es la crítica que Berner dirige a Gertz. ${ }^{106}$ No obstante, los procesos son en parte análogos. O mejor dicho, la investigación sobre un texto medular como Ex 14 abre un acceso, entre los múltiples posibles, a la compresión de cómo ha sido la compleja relación entre estos dos universos literarios (Priesterschrift y Nichtpriesterschrift) para dar a luz a la Torah.

El camino que queda a la exégesis es largo y arduo (cf. 1 R 19,7) y no rara vez a los ojos de muchos los frutos inmediatos (¿o inmediatistas?) son escasos. La fatiga no siempre se compensa con el reconocimiento. Sin embargo, esto es lo que hace de la investigación y de la exégesis una tarea apasionante y forma parte de su "belleza". Aquí puede verificarse la sabiduría de aquellas palabras del personaje de Victor Hugo que, ante la propuesta de su ama de llaves de deshacerse de una planta de flores por su "inutilidad", replica con contundencia:

"Le beau est aussi utile que l'utile." II ajouta après un silence: "Plus peut-être". ${ }^{107}$

ADRIÁN TARANZANO

106 Cf. C. BERNER, Die Exoduserzählung. p. 2. El autor critica no obstante la pretensión de Gertz de expresarse sobre la redacción de todo el Pentateuco sólo a partir del análisis de Ex 1-15.

107 Victor Hugo, Les misérables, I, III. 
MÜNCHEN

ataranzano@hotmail.com 